\title{
Estética urbana: uma análise através das ideias de ordem, estímulo visual, valor histórico e familiaridade
}

Urban aesthetics: an analysis through the ideas of order, visual stimulus, historical value and familiarity

\footnotetext{
Antônio Tarcísio da Luz Reis

Camila Damiani Biavatti

Maria Lourdes Pereira

Antônio Tarcísio da Luz Reis

Departamento de Arquitetura, Faculdade de Arquitetura Universidade Federal do Rio Grande

do Sul

Rua Sarmento Leite, 320, Centro Porto Alegre - RS - Brasil 90050-170

Tel.: (51) 3308-4529

E-mail: tarcisio@orion.ufrgs.br

Camila Damiani Biavatti

Departamento de Arquitetura,

Faculdade de Arquitetura e

Urbanismo

Universidade Federal do Rio Grande

do Sul

Rua Sarmento Leite, 320, Sala 209,

Centro

Porto Alegre - RS - Brasil

CEP $90050-170$

Tel.: (51) 3308-4002

E-mail: camila_biavatti@hotmail.com

Maria Lourdes Pereira Departamento de Arquitetura,

Faculdade de Arquitetura e

Universidade Federal do Rio Grande

E-mail: mlseadi@hotmail.com

Recebido em 13/09/11

Aceito em 26/12/11

\section{Resumo}

$\mathbf{E}$

ste artigo examina a dicotomia entre a abordagem da estética filosófica e a da estética empírica, assim como os impactos da estética formal e da estética simbólica, a partir das respostas de usuários do espaço urbano de Porto Alegre. São investigados os impactos estéticos

causados por cenas urbanas com diferentes níveis de ordem e estímulo visual, com e sem valor histórico, e com diferentes níveis de familiaridade. É também examinada a existência ou não de diferenças entre as respostas estéticas de arquitetos, não arquitetos com curso superior e pessoas com o primeiro ou segundo grau. Ainda, são identificadas as razões para as avaliações realizadas por esses três grupos. Os principais resultados evidenciam o potencial da estética empírica em explicar as avaliações estéticas e revelam o impacto positivo e preponderante da ideia de ordem e estímulo visual em tais avaliações.

Palavras-chave: Estética urbana. Ordem. Estímulo visual. Valor historico. Familiaridade.

\section{Abstract}

This paper examines the dichotomy between the philosophical and the empirical aesthetics approaches, as well as the impact of formal and symbolic aesthetics, considering the responses from users of the urban area of Porto Alegre. The aesthetic impacts caused by urban scenes with different levels of order and visual stimuli, with and without historical value and with different levels of familiarity are investigated. The existence of differences between the aesthetic responses of architects, non-architects college graduates and non college graduates is also examined. Still, the reasons for the assessments conducted by these three groups are identified. The main results show the potential of empirical aesthetics to explain aesthetic evaluations, and reveal the dominant and positive impact of the idea of order and visual stimuli in such evaluations.

Keywords: Urban aesthetics. Order. Visual stimulus. Historical value. Familiarity.
} 


\section{Introdução}

O termo "estética" (aesthetics) foi concebido pelo filósofo Alexander Baumgarten em 1750 para indicar o estudo do gosto nas belas artes, ou seja, a percepção de beleza principalmente no tocante à poesia, à pintura e à escultura (LANG, 1987). Hoje, estética também pode ser entendida como aquela característica dos elementos construídos ou naturais que sensibilizam nossos sentidos e afetam nossas emoções. Logo, estética diz respeito àqueles elementos do espaço urbano que estimulam nossos sentidos, incluindo as sensações não visuais, embora as visuais sejam dominantes (por exemplo, Porteous, 1996).

Além do impacto positivo sobre a qualidade de vida dos cidadãos, a existência de qualidade estética tem influência significativa no turismo e, portanto, na economia de uma cidade. Assim, a avaliação estética tem sido implementada em países como os Estados Unidos, França, Espanha, Alemanha, Itália, Holanda, Japão e Reino Unido. Nos Estados Unidos, a aparência de um projeto é considerada para avaliar seu impacto ambiental, podendo servir, inclusive, de base para iniciativas de políticas públicas e de associações de melhorias de centros urbanos. Ainda, a Suprema Corte dos Estados Unidos julga suficientes as considerações estéticas para o estabelecimento de regulamentações, argumentando que a qualidade estética do espaço urbano é de interesse público e não deve estar baseada no gosto pessoal de funcionários do governo, mas nas preferências da população (SANOFF, 1991; REIS; LAY, 2003, 2006).

A importância da aparência de um ambiente para seus usuários tem sido citada em diversos estudos (por exemplo, Reis e Lay, 2003). Por exemplo, a qualidade estética de conjuntos habitacionais tem sido apontada como um fator determinante para a satisfação de seus residentes e confirmada, no contexto brasileiro, como um aspecto habitacional de grande importância (REIS, 2002; REIS; LAY, 2003). A experiência urbana esteticamente agradável também tem sido mencionada como um dos três principais objetivos do desenho urbano:

\begin{abstract}
$O$ desenho das cidades e as políticas de zoneamento possuem três objetivos principais. Somando-se à eficiência social e econômica e saúde biológica, a cidade deveria prover aos seus cidadãos com uma "experiência estética e sensorial contínua e satisfatória." [JACKSON, $1959^{l}$, p. 11]. (apud PORTEOUS, 1996, p. 88).
\end{abstract}

\footnotetext{
1 JACKSON, J. B. The Imitation of Nature. Landscape, v. 9, n. 1 , p. 9-12, autumn 1959.
}

Evidencia-se, também, a importância da estética urbana para a sustentabilidade social, uma das três ênfases do desenvolvimento sustentável (juntamente com as sustentabilidades econômica e ecológica), que visa aspectos socioculturais, incluindo as atitudes e os comportamentos dos usuários da cidade (SADAN; CHURCHMAN, 1997).

As análises e/ou avaliações estéticas enquadram-se na estética empírica, que juntamente com a estética filosófica constituem as duas principais abordagens estéticas. A estética filosófica é metafísica, engloba o estudo do processo criativo, pressupondo que "a beleza está nos olhos de quem vê" e sugerindo que as reações estéticas de pessoas diferentes, diante de um mesmo objetivo, seriam distintas, inviabilizando o consenso estético e, consequentemente, a realização de avaliações sobre o tema. Segundo Ruskin $\left(1885^{2}\right.$ apud LANG, 1987), valores estéticos não podem ser objeto de estudos científicos. A estética empírica, por outro lado, busca entender "O que proporciona prazer às pessoas e por quê.” (LANG, 1987, p. 179), tendo como base que a beleza está mais no objeto que é percebido do que nos olhos de quem percebe. A estética empírica engloba os processos de percepção e cognição, assumindo a ideia de que é possível avaliar as reações estéticas de pessoas diferentes e obter resultados semelhantes, o que permite, em última instância, identificar consensos estéticos e aplicá-los em intervenções urbanas, qualificando o espaço urbano e a vida de seus usuários.

A estética empírica, por sua vez, é constituída pela estética formal e pela estética simbólica. A estética formal lida com a percepção visual da composição arquitetônica das edificações, dos atributos formais percebidos em um edifício, tais como suas dimensões, esquemas cromáticos utilizados e geometria, e de suas relações (LANG, 1987), e “[...] resulta de um processo de organização perceptiva, a qual é funcionalmente independente do processo de organização cognitiva [...]" (WEBER, 1995, p. 74). Assim, salienta-se que a:

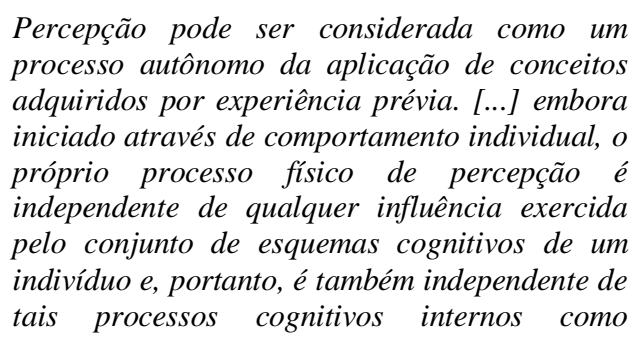

${ }^{2}$ RUSKIN, J. Stones of Venice. Boston: Estes and Lauriat Publishers, 1885. 
imaginação, memória e reconhecimento. (WEBER, 1995, p. 74-77).

Conforme evidenciado pela teoria de Gestalt, padrões formais possibilitam respostas estéticas similares para indivíduos com formações culturais distintas (PRAK, 1985). Assim, o processo de percepção pode explicar a similaridade entre as respostas estéticas de distintas pessoas a determinado padrão formal (ARNHEIM, 1977; PRAK, 1985; VON MEISS, 1993). Embora o processo de percepção também trate dos estímulos relacionados aos demais sentidos, o termo "percepção" tende a estar relacionado à percepção visual, uma vez que a visão é o sentido dominante, responsável por mais de $80 \%$ do estímulo sensorial humano, com o restante ficando a cargo da audição, do olfato e do tato (PORTEOUS, 1996; REIS; LAY, 2006).

$\mathrm{O}$ processo de percepção visual, intrínseco à estética formal, tenderia a explicar reações estéticas diferenciadas a diferentes níveis de ordem e estímulo visual. Weber (1995, p. 10) ressalta que “[...] ordem perceptiva é uma consequência de processos fisiológicos que estão baseados em princípios biológicos natos [...]" (WEBER, 1995, p. 110). $\mathrm{O}$ efeito positivo de ordem estaria condicionado à existência de estímulo visual, gerado por contrastes ou variações controladas (PURCELL, 1984; LOZANO, 1988; MARTINDALE, 1988; PORTEOUS, 1996; NASAR, 1998). Assim, as avaliações estéticas positivas de áreas históricas seriam em função da consistência formal existente tanto entre os elementos que compõem as edificações quanto entre elas, assim como pela presença de estímulo visual. Esse aspecto, juntamente com a existência de organização, poderia justificar a satisfação com a aparência de fachadas em outras áreas urbanas (PRAK, 1985; LANG, 1987, 1988; GROAT, 1988; NASAR, 1997, 1998).

A estética simbólica, por sua vez, trata das associações estabelecidas com os elementos físicos e naturais em uma cena urbana, como resultado do processo de cognição. A distinção entre os processos de percepção e cognição explica a distinção entre atributos formais e significados associados às edificações no espaço urbano. $\mathrm{O}$ significado, em oposição à forma, trata de interpretações pelas quais é atribuído valor, com base em conceitos extramórficos (WEBER, 1995; REIS; LAY, 2006), independentes, portanto, de padrões de estímulo. A estética simbólica torna-se importante para suprir a necessidade de identidade dos indivíduos (LANG, 1987). Os valores, consciente ou inconscientemente atribuídos aos ambientes naturais e construídos por um indivíduo, variam conforme aspectos fisiológicos, psicológicos e sociais. Desse modo, os significados simbólicos devem ser entendidos como uma fração integrante do vasto conjunto de valores constituintes de uma cultura. Nesse sentido, alguns estudos indicam a possibilidade de a formação intelectual dos indivíduos interferir significativamente em suas respostas estéticas, por exemplo, criando diferenças nas avaliações entre arquitetos e leigos (LANG, 1987, p. 213-214). Decorre que em determinado estudo foram obtidas diferenças significativas entre as preferências estéticas de arquitetos e leigos usuários de edifícios de escritórios com relação a suas fachadas (FAWCETT; ELLINGHAM; PLATT, 2008).

Segundo alguns estudos, o nível de familiaridade com a cena urbana também pode afetar sua avaliação estética. Nesse sentido, Porteous (1996, p. 124) salienta que as pessoas são claramente influenciadas em suas respostas estéticas por características pessoais que incluem, além dos aspectos socioeconômicos, demográficos e culturais, a familiaridade. Por exemplo,

\section{[...] estudos de imagens urbanas (LYNCH, $1960^{3}$; APPLEYARD, $1969^{4}$; PORTEOUS, $1977^{5}$ ) tem encontrado que a familiaridade dos respondentes com os próprios lugares sendo avaliados, ou com lugares similares, é um fator principal que influencia as preferências pelas paisagens (BECKETT, $1974^{\circ}$; JACKSON; HUDMAN; ENGLAND, $1978^{7}$; NIEMAN, 1980'; CLAMP, 1981') [...]. (apud PORTEOUS, 1996, p. 125-126).}

Adicionalmente, "[...] o efeito de novidade e familiaridade no julgamento estético de edifícios individuais é demonstrado por Herzog, Kaplan, e Kaplan $(1976)^{10}[\ldots]$ ".. (apud HEATH, 1988, p. 7). Familiaridade pode também afetar preferência:

\footnotetext{
${ }^{3} \mathrm{LYNCH}, \mathrm{K}$. The Image of the City. Cambridge, MA; MIT Press, 1960.

${ }^{4}$ APPLEYARD, D. Why Buildings Are Known. Environment and Behavior, v. 1, p. 131-56, dec. 1969.

${ }^{5}$ PORTEOUS, J. D. Environment \& Behavior: planning and everyday urban life. Reading, MA; Addison-Wesley, 1977.

${ }^{6}$ BECKETT, P. H. T. The Interaction Between Knowledge and Aesthetic Appreciation. Landscape Research News, v. 1, n. 8 p. 5-7, summer 1974 .

7 JACKSON, R. H.; HUDMAN, L. E.; ENGLAND, J. L. Assessment of the Environmental Impact of High Voltage Power Transmission Lines. Journal of Environmental Management, v. 6, n. 2, p. 153-170, 1978

${ }^{8}$ NIEMAN, T. J. The Visual Environment of the New York Coastal Zone: user preferences and perceptions. Coastal Zone Management Journal, v. 8, p. 45-62, 1980.

${ }^{9}$ CLAMP, P. The Landscape Evaluation Controversy. Landscape Research, v. 6, n. 2, p. 13-15, 1981.

${ }^{10}$ HERZOG, T. R.; KAPLAN, S.; KAPLAN, R. The Prediction of Preference for Familiar Urban Places. Environment and Behavior, v. 8, n. 4, p. 627-456, 1976.
} 
"preferência também pode estar relacionada à familiaridade e frequência de exposição, levando a diferentes padrões de preferência entre os dois grupos (residentes e visitantes) (BORNSTEIN, $1989^{11}$; MORELAND; ZAJONC, 1977 $\left.{ }^{12}, 1979^{13}\right)$ ", (apud NASAR, 1998, p. 37).

O significado ou valor histórico também parece ter um impacto sobre a avaliação estética segundo alguns estudos. Conforme Nasar (1998), a aparência histórica tende a evocar respostas favoráveis e tende a ser uma razão para as pessoas gostarem de um lugar. Por exemplo, a percepção de lugares com significado histórico foi uma das cinco características atraentes encontradas por Nasar (1998) em seu estudo sobre as imagens das cidades americanas de Knoxville e Chattanooga:

Lugares podem ter significado histórico
autêntico ou parecer históricos para os
observadores. Em ambos os casos, tais lugares
evocam respostas favoráveis. As pessoas
frequentemente diziam que gostavam de um
lugar devido à sua aparência ou associações
históricas. (NASAR, 1998, p. 62).

O impacto do significado histórico sobre a imagem urbana tem sido mostrado em outros estudos. Por exemplo, pesquisas (EVANS; SMITH; PEZDEK, $1982^{14}$; LYNCH, $1960^{15}$ apud NASAR, 1998, p. 72) têm mostrado que o significado histórico aumenta a imageabilidade de um edifício como um referencial urbano e pode auxiliar (EVANS et al., $1984^{16}$ apud NASAR, 1998, p. 72) especialmente os idosos a lembrarem-se e orientarem-se em ambientes urbanos (NASAR, 1998). Embora a importância do significado associado a edificações históricas pareça estar bem evidenciada na literatura, não está conclusivamente evidenciado que avaliações estéticas positivas de tais edificações sejam, fundamentalmente, em função do que elas significam em termos históricos para as pessoas ou em função de suas características arquitetônicas, normalmente expressando a ideia

\footnotetext{
${ }^{11}$ BORNSTEIN, R. F. Exposure and Affect: overview and metaanalysis of research, 1968-1987. Psychological Bulletin, v. 106, n. 2, p. 265-289, 1989.

${ }^{12}$ MORELAND, R. L.; ZAJONC, R. B. Is Stimulus Recognition a Necessary Condition for the Occurrence of Exposure Effects? Journal of Personality and Social Psychology, v. 35, n. 4, p. 191-199, abr. 1977.

${ }^{13}$ MORELAND, R. L.; ZAJONC, R. B. Exposure Effects May Not Depend on Stimulus Recognition. Journal of Personality and Social Psychology, v. 37, n. 6, p. 1085-1089, 1979.

${ }^{14}$ EVANS, G.; SMITH, C.; PEZDEK, K. Cognitive Maps and Urban Form. Journal of the American Planning Associaiton, v. 48, n. 2, p. 232-244, spring 1982.

${ }^{15}$ LYNCH, K. The Image of the City. Cambridge, MA; MIT Press, 1960.

${ }^{16}$ EVANS, G. W. et al. Cognitive Mapping and Elderly Adults: verbal and locational memory for urban landmarks. Journal of Gerontology, v. 39, n. 4, p. 452-457, 1984.
}

de ordem e estímulo visual. Por exemplo, referindo-se à pesquisa realizada por Milgram e Jodelet (1976) ${ }^{17}$ em Paris, Nasar (1998, p. 70) escreveu que os parisienses " [...] geralmente reclamavam sobre a substituição do grande charme das antigas estruturas por apartamentos e escritórios modernos [...]", indicando que os aspectos formais das edificações antigas eram preferidos aos das edificações modernas. Nasar (1998) também ressalta que as pessoas podem responder favoravelmente às edificações históricas porque o conteúdo histórico ressalta a imageabilidade da edificação e, então, melhora a legibilidade urbana; porque edificações históricas podem evocar associações favoráveis com o passado ou com o status percebido; ou porque edificações e áreas urbanas antigas possuem a mescla preferida de ordem e variedade. Com relação a esta última, Nasar (1998, p. 72) argumenta que, "[...] embora cada edificação ou elemento possam ser distintos, eles tendem a enquadrar-se em um padrão reconhecível, conexo à ordem percebida [...]".

Assim, parece haver necessidade de aprofundar o conhecimento sobre a possibilidade de explicar as reações estéticas das pessoas com base em justificativas que remetam à ideia de ordem e estímulo, sustentando a abordagem da estética empírica em contraposição à da estética filosófica. Ainda, faz-se necessária uma maior compreensão sobre o impacto de aspectos associados à estética simbólica, tais como familiaridade e valor histórico, nas avaliações estéticas, em comparação com os conceitos de ordem e estímulo visual, intrínsecos à estética formal. Também é relevante haver um melhor entendimento, principalmente na realidade brasileira, sobre as avaliações estéticas de pessoas com distintos níveis e tipos de formação acadêmica. Nesse sentido, avaliações por indivíduos com diferentes tipos e níveis de formação acadêmica de cenas urbanas com distintos níveis de ordem e estímulo visual, familiaridade e valor histórico podem gerar conhecimentos adicionais no que se refere à dicotomia entre a estética filosófica e a empírica e ao melhor entendimento do impacto da estética formal e simbólica.

Portanto, o objetivo deste artigo é examinar a dicotomia entre a abordagem da estética filosófica e a da estética empírica, assim como o impacto da estética formal e da estética simbólica, mediante respostas de usuários do espaço urbano de Porto Alegre. Especificamente, são investigados os

\footnotetext{
${ }^{17}$ MILGRAM, S.; JODELET, D. Psychological Maps of Paris. In: PROSHANSKY, H.; ITTLESON, W.; RIVLIN, L. (Eds.). Environmental Psychology: people and their physical settings. $2^{\text {nd }}$ ed. New York: Holt, Rinehart \& Winston, 1976. p. 104-124.
} 
impactos estéticos causados por cenas urbanas com diferentes níveis de ordem e estímulo visual, com e sem valor histórico, e com diferentes níveis de familiaridade. É também examinada a existência de diferenças ou não entre as respostas estéticas de arquitetos, não arquitetos com curso superior e pessoas com o primeiro ou segundo grau. Ainda, são identificadas as razões para as avaliações realizadas por esses três grupos.

\section{Metodologia}

Para responder aos objetivos acima explicitados, foram coletados dados por meio de questionários e entrevistas estruturadas aplicados a 60 arquitetos (em sua expressiva maioria professores da Faculdade de Arquitetura da UFRGS), 60 não arquitetos com formação superior (majoritariamente professores da Escola de Engenharia e das Faculdades de Educação, Economia e Direito da UFRGS) e 60 respondentes com o primeiro ou segundo grau (funcionários das Faculdades de Arquitetura, Educação, Economia e Direito, da Escola de Engenharia e da Reitoria da UFRGS). Como critério de participação, o respondente deveria residir ou trabalhar em Porto Alegre há pelo menos um ano, de modo a caracterizar uma relação de familiaridade com a cidade. Ainda, os respondentes da categoria de não arquitetos com formação superior não deveriam ser graduados em cursos cujos conteúdos tratassem de estética, tais como Artes Plásticas, Artes Visuais, Design Gráfico e Design do Produto, de maneira a caracterizar uma amostra sem formação estética, ao contrário da amostra dos arquitetos.

Os questionários eram constituídos por perguntas fechadas de escolha simples e de escolha múltipla, acerca da avaliação da aparência de cenas urbanas; da preferência delas quanto à aparência; da classificação de cada cena como familiar ou não familiar; e da indicação das principais razões que justificam a cena mais preferida e a cena menos preferida. As entrevistas estruturadas tinham o intuito de aprofundar o conhecimento sobre o impacto da estética simbólica especificamente quanto à familiaridade e ao valor histórico das cenas, mediante solicitações de explicações aos entrevistados sobre possíveis impactos desses aspectos nas avaliações das cenas (por exemplo, "Explique se o fato de alguma cena lhe ser familiar afetou a sua avaliação”). O tempo médio gasto na aplicação dos questionários e na realização subsequente das entrevistas, pelos dois pesquisadores, foi de $30 \mathrm{~min}$.

As cenas urbanas, cada uma representando uma quadra com $100 \mathrm{~m}$, foram apresentadas pelos pesquisadores durante a aplicação dos questionários através de um kit fotográfico constituído por três pranchas em formato $\mathrm{A} 3$, com duas cenas históricas de Florença e uma de Praga (Figura 1), três cenas históricas de Porto Alegre (Figura 2) e três cenas contemporâneas de Porto Alegre (Figura 3). Essas cenas foram categorizadas conforme se segue:

(a) cena histórica de Florença com ordem e pouco estímulo (Figura 4);

(b) cena histórica de Florença com desordem (Figura 5);

(c) cena histórica de Praga com ordem e estímulo (Figura 6);

(d) cena histórica de Porto Alegre com ordem e estímulo (Figura 7);

(e) cena histórica de Porto Alegre com desordem (Figura 8);

(f) cena histórica de Porto Alegre com ordem e pouco estímulo (Figura 9);

(g) cena contemporânea de Porto Alegre com desordem (Figura 10);

(h) cena contemporânea de Porto Alegre com ordem e estímulo (Figura 11); e

(i) cena contemporânea de Porto Alegre com ordem e pouco estímulo (Figura 12).

A quantidade e as dimensões das cenas em cada prancha foram determinadas de modo a facilitar a compreensão e a comparação entre as cenas pelos participantes da pesquisa, enquanto o tamanho da prancha foi também definido de maneira a facilitar seu manuseio pelos participantes assim como sua portabilidade quando dos deslocamentos dos dois pesquisadores para a aplicação dos questionários e realização das entrevistas. A utilização de fotografias coloridas nas cenas está fundamentada no uso recorrente delas em estudos envolvendo avaliações estéticas e na adequação delas em simular um ambiente real (SANOFF, 1991). 
Figura 1 - Prancha com cenas históricas de Florença e Praga

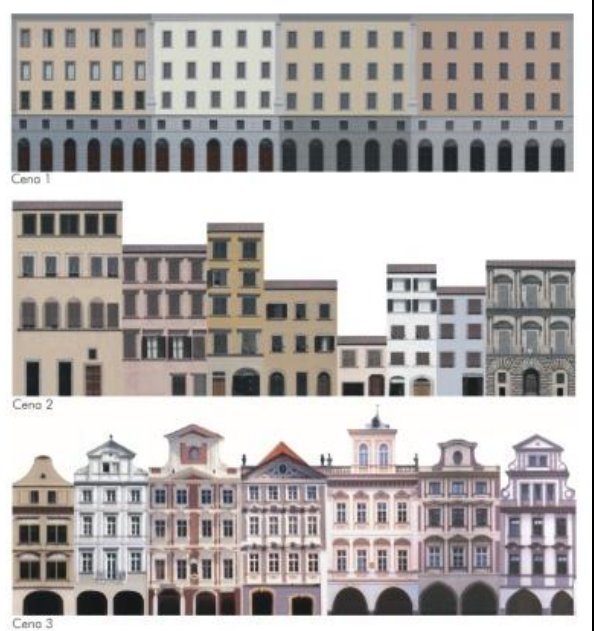

\section{Figura 1 - Prancha com cenas historicas de Florença e Praga}

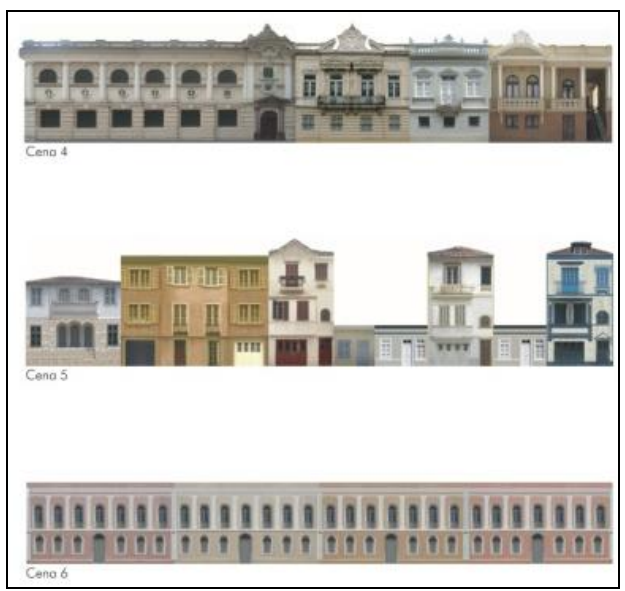

Figura 2 - Prancha com cenas históricas de Porto Alegre

Figura 3 - Prancha com cenas contemporâneas de Porto Alegre
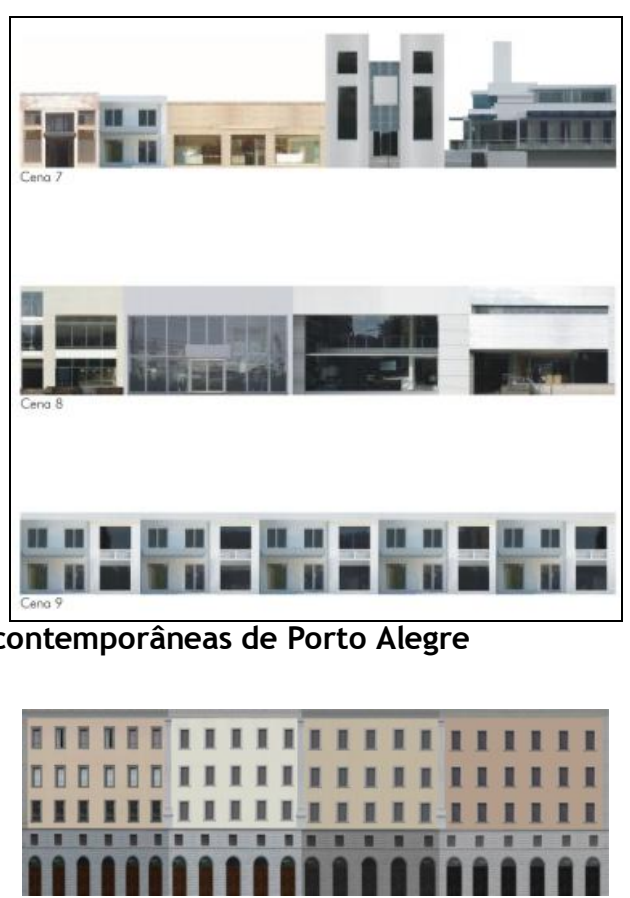

Figura 4 - Cena (1) histórica de Florença com ordem e pouco estímulo

190 Reis, A. T. da L.; Biavatti, C. D.; Pereira, M. L. 
Figura 5 - Cena (2) histórica de Florença com desordem
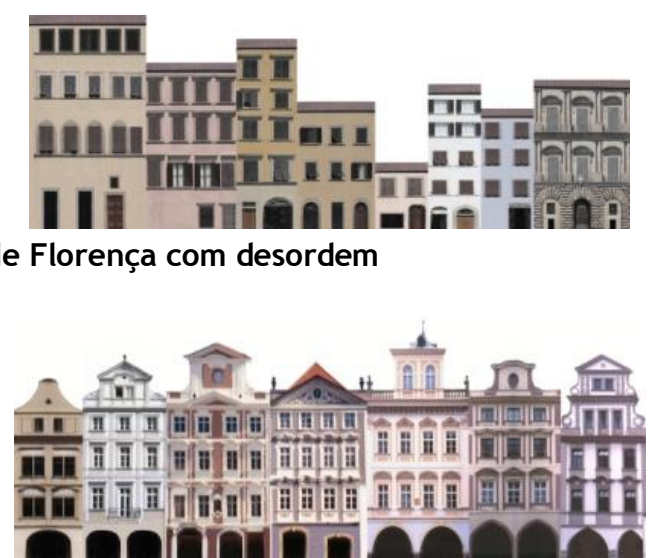

Figura 6 - Cena (3) histórica de Praga com ordem e estímulo

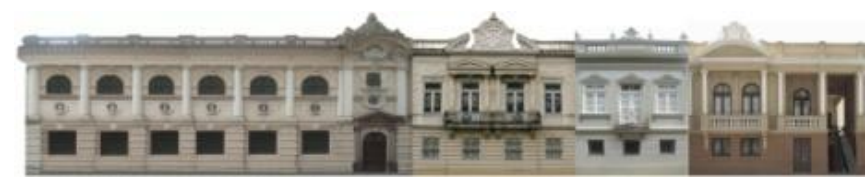

Figura 7 - Cena (4) histórica de Porto Alegre com ordem e estímulo

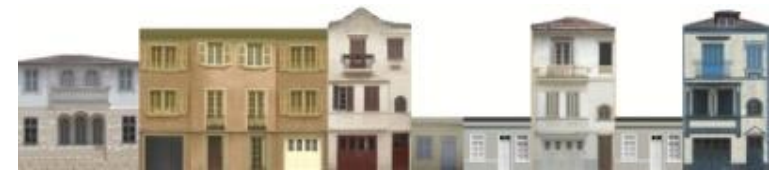

Figura 8 - Cena (5) histórica de Porto Alegre com desordem

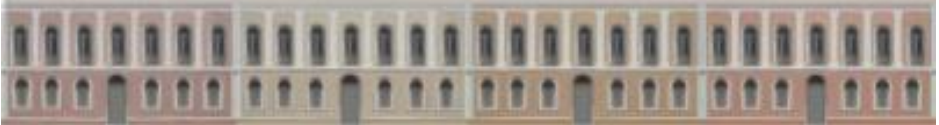

Figura 9 - Cena (6) histórica de Porto Alegre com ordem e pouco estímulo

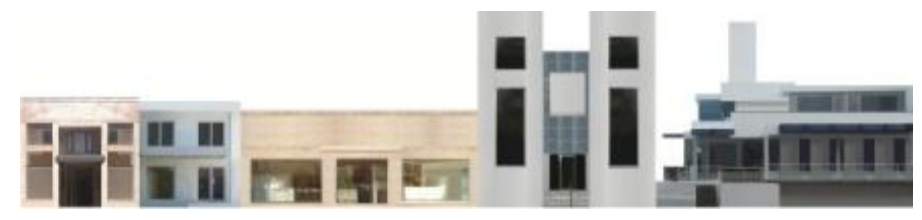

Figura 10 - Cena (7) contemporânea de Porto Alegre com desordem

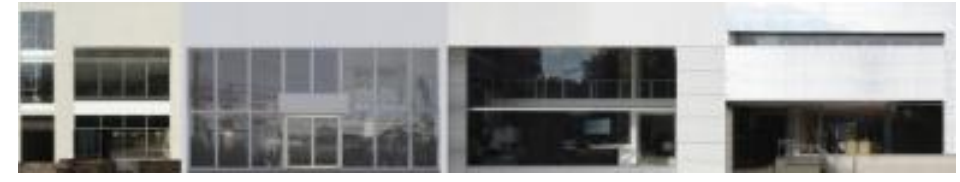

Figura 11 - Cena (8) contemporânea de Porto Alegre com ordem e estímulo

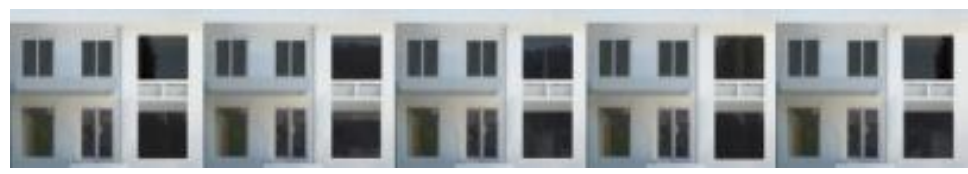

Figura 12 - Cena (9) contemporânea de Porto Alegre com ordem e pouco estímulo 
Cenas com ordem e estímulo visual são caracterizadas por uma clara organização dos elementos arquitetônicos e compatibilidade entre as edificações que as compõem, com claro estímulo visual provocado por focos de atenção (Figuras 6, 7 e 11). Cenas com ordem e pouco estímulo visual são caracterizadas por uma clara organização dos elementos arquitetônicos e compatibilidade entre as edificações que as compõem, mas com baixo estímulo visual, o que pode gerar monotonia (Figuras 4, 9 e 12). Cenas com desordem são caracterizadas por falta de organização, tanto entre as edificações que as compõem quanto entre os elementos arquitetônicos delas (Figuras 5, 8 e 10).

As cenas históricas de Florença e de Praga são compostas de edificações que fazem parte de suas áreas históricas. As cenas históricas de Porto Alegre são constituídas por edificações consideradas de valor histórico e/ou artístico e tombadas por instituições públicas em nível local (Equipe do Patrimônio Histórico e Cultural EPAHC), estadual (Instituto do Patrimônio Histórico e Artístico do Estado do Rio Grande do Sul - IPHAE) e federal (Instituto do Patrimônio Histórico e Artístico Nacional - IPHAN), responsáveis por preservar o patrimônio cultural. Essas cenas possibilitam a análise do impacto estético de cenas com distintos níveis de familiaridade e de valor histórico. As cenas contemporâneas de Porto Alegre são formadas por edificações comerciais construídas a partir de 1990 que não se caracterizam como obras arquitetônicas de referência e/ou de divulgação pela mídia. As edificações nas nove cenas possuem, no máximo, quatro pavimentos, de maneira que as cenas históricas e contemporâneas guardem uma relação de escala e correspondam às categorias de ordem com estímulo, ordem com pouco estímulo e desordem. As fotografias das edificações foram editadas no programa Corel Photo Paint visando às montagens de cenas sem distorções e sem pessoas, veículos, sombras e elementos urbanos, tais como vegetação, postes e fios de luz, e lixeiras, que pudessem interferir na avaliação estética das cenas (por exemplo, Figuras 13 e 15). Ainda, foram realizadas alterações na composição de algumas edificações, de modo a adequá-las às cenas (por exemplo, Figuras 14 e 16). Assim, as cenas foram caracterizadas por montagens fotográficas que respondessem aos objetivos da investigação.

Figura 13 - Palacete Argentina - tombado pelo Iphan
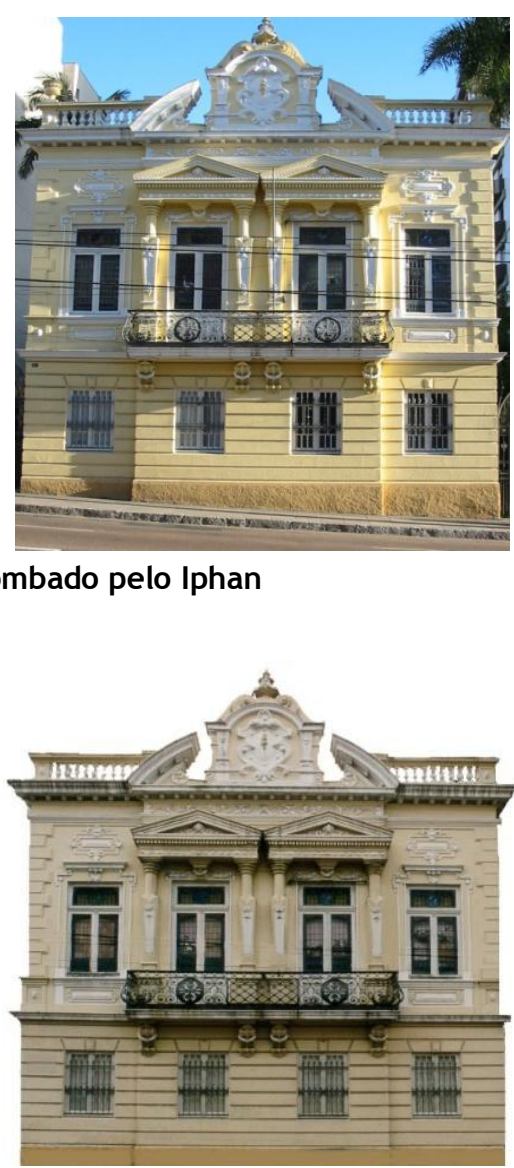

Figura 14 - Palacete Argentina - editado no programa Corel Photo Paint 


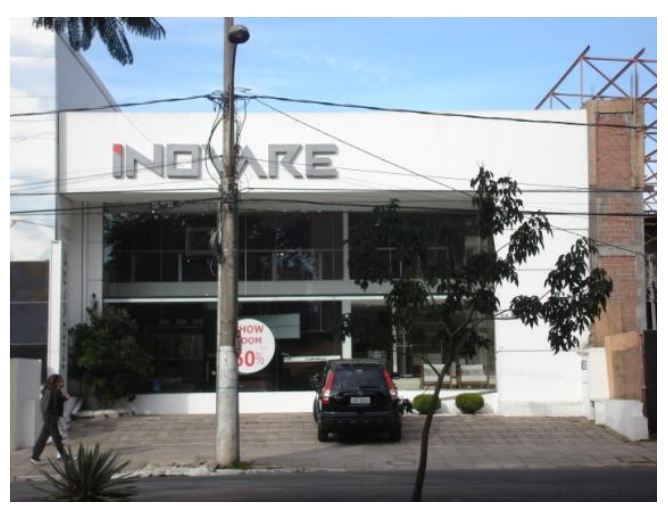

Figura 15 - Loja Inovare - edificação contemporânea

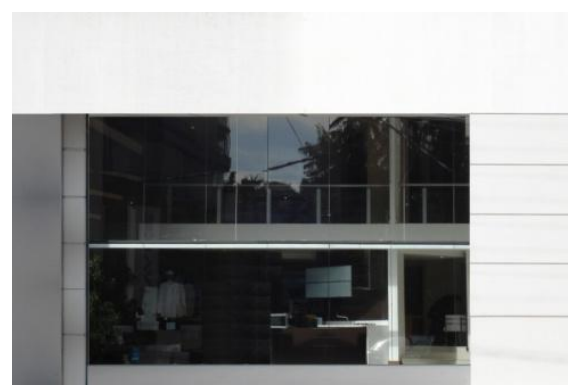

Figura 16 - Loja editada no programa Corel Photo Paint

Foram realizados três testes, incluindo o estudo piloto, e elaboradas mais de cem cenas para verificar a adequação delas às categorias estabelecidas. O estudo piloto, composto do questionário, entrevista e cenas, foi realizado com quinze participantes, sendo cinco arquitetos, cinco não arquitetos com formação superior e cinco pessoas sem formação superior, funcionários e professores da Faculdade de Arquitetura da UFRGS. Os principais objetivos do estudo piloto foram:

(a) a compreensão das questões;

(b) a verificação da representatividade das cenas no que diz respeito às características de cada uma das três categorias estéticas (ordem e estímulo, ordem e pouco estímulo, e desordem); e

(c) o tempo médio necessário para completar o questionário e as entrevistas.

Os dados obtidos por meio dos questionários foram tabulados no programa estatístico $P A S W$ Statistics 8 e analisados por meio de testes estatísticos não paramétricos como Kruskal-Wallis e Kendall W. O primeiro identifica a existência de uma diferença estatisticamente significativa entre as avaliações realizadas por cada um dos três grupos de respondentes para cada uma das nove cenas. O último revela a presença de uma diferença estatisticamente significativa entre as avaliações realizadas para as nove cenas por cada um dos três grupos. Os dados das entrevistas (respostas a questões do tipo "Explique se o fato de alguma cena ser antiga ou ter valor histórico afetou a sua avaliação") foram analisados através das frequências e significados das respostas.

\section{Resultados}

Conforme os objetivos da investigação, são apresentados, a seguir, os resultados.

\section{Dicotomia entre estética filosófica e estética empírica}

A dicotomia entre a abordagem da estética filosófica e a da estética empírica é abordada a partir dos resultados obtidos com as avaliações das nove cenas com diferentes níveis de ordem e estímulo visual. Através do teste estatístico Kendall W, são identificadas diferenças entre as avaliações das nove cenas pelo total dos 180 respondentes e pelos respondentes de cada grupo.

Uma diferença estatisticamente significativa foi encontrada entre as avaliações das aparências das cenas efetuadas pela amostra total de 180 respondentes (Kendall $\mathrm{W}, \chi^{2}=403.63$, sig. $=$ $0,000)$, pela amostra de arquitetos (Kendall W, $\chi^{2}$ $=174,44$, sig. $=0,000)$, pela amostra de não arquitetos com formação superior (Kendall $\mathrm{W}, \chi^{2}=$ $162,48$, sig. $=0,000)$ e pela amostra de respondentes sem formação superior (Kendall W, 
$\chi^{2}=110,89$, sig. $\left.=0,000\right)$. Essas diferenças evidenciam que cenas com distintos níveis de ordem e estímulo visual são avaliadas diferentemente.

As cenas consideradas mais satisfatórias esteticamente para a amostra total de 180 respondentes são as seguintes (Tabela 1 e Quadro 1):

(a) cena 3: Figura 6;

(b) cena 4: Figura 7;

(c) cena 6: Figura 9; e

(d) cena 8: Figura 11.

A cena 3 (Figura 6 - cena histórica de Praga com ordem e estímulo) foi classificada pela expressiva maioria da amostra total $(84,4 \%)$ como bonita ou muito bonita, sendo a cena esteticamente mais satisfatória entre as nove analisadas (Tabela 1 e
Quadro 1). A cena 4 (Figura 7 - cena histórica de Porto Alegre com ordem e estímulo) foi também julgada como bonita ou muito bonita pela maioria $(78,9 \%)$ da amostra total de 180 respondentes, sendo a segunda cena esteticamente mais satisfatória. A cena 6 (Figura 9 - cena histórica de Porto Alegre com ordem e pouco estímulo) foi considerada bonita ou muito bonita por $44,5 \%$ da amostra total de respondentes, sendo esteticamente bem mais satisfatória do que insatisfatória $(18,9 \%)$. No entanto, uma parcela expressiva $(36,7 \%)$ julgou-a nem bonita nem feia (Tabela 1$)$, resultado que pode ser justificado em função da presença da ideia de ordem e do pouco estímulo existente. A cena 8 (Figura 11 - cena contemporânea de Porto Alegre com ordem e estímulo) foi considerada bonita ou muito bonita por $43,4 \%$ da amostra total de respondentes, sendo também bem mais satisfatória esteticamente do que insatisfatória $(22,2 \%)$ (Tabela 1$)$.

Tabela 1 - Graus de satisfação com a aparência das cenas

\begin{tabular}{|c|c|c|c|c|c|c|c|c|c|}
\hline N satisfação & $\begin{array}{c}\text { Cena } 1 \\
\text { Fig. } 4\end{array}$ & $\begin{array}{c}\text { Cena } 2 \\
\text { Fig. } 5\end{array}$ & $\begin{array}{c}\text { Cena } 3 \\
\text { Fig. } 6\end{array}$ & $\begin{array}{c}\text { Cena } 4 \\
\text { Fig. } 7\end{array}$ & $\begin{array}{c}\text { Cena } 5 \\
\text { Fig. } 8\end{array}$ & $\begin{array}{c}\text { Cena } 6 \\
\text { Fig. } 9\end{array}$ & $\begin{array}{l}\text { Cena } 7 \\
\text { Fig. } 10\end{array}$ & $\begin{array}{l}\text { Cena } 8 \\
\text { Fig. } 11\end{array}$ & $\begin{array}{l}\text { Cena } 9 \\
\text { Fig. } 12 \\
\end{array}$ \\
\hline \multicolumn{10}{|c|}{ Total da amostra -180 respondentes } \\
\hline Muito bonita & $7,2 \%$ & $3,3 \%$ & $47,2 \%$ & $30,6 \%$ & $5,0 \%$ & $7,8 \%$ & $5,6 \%$ & $10,6 \%$ & $4,4 \%$ \\
\hline Bonita & $24,4 \%$ & $25,0 \%$ & $37,2 \%$ & $48,3 \%$ & $21,7 \%$ & $36,7 \%$ & $25,6 \%$ & $32,8 \%$ & $18,9 \%$ \\
\hline $\mathrm{N}$ bonita $\mathrm{n}$ feia & $47,8 \%$ & $37,2 \%$ & $10,6 \%$ & $13,9 \%$ & $29,4 \%$ & $36,7 \%$ & $23,9 \%$ & $34,4 \%$ & $39,4 \%$ \\
\hline Feia & $14,4 \%$ & $30,6 \%$ & $4,4 \%$ & $6,1 \%$ & $32,8 \%$ & $16,1 \%$ & $33,9 \%$ & $18,3 \%$ & $23,9 \%$ \\
\hline Muito feia & $6,1 \%$ & $3,9 \%$ & $0,6 \%$ & $1,1 \%$ & $11,1 \%$ & $2,8 \%$ & $11,1 \%$ & $3,9 \%$ & $13,3 \%$ \\
\hline mvo Kendall & 4,65 & 4,23 & 7,42 & 6,93 & 3,78 & 5,13 & 3,97 & 5,07 & 3,81 \\
\hline \multicolumn{10}{|c|}{ Arquitetos -60 respondentes } \\
\hline Muito bonita & $10,0 \%$ & $3,3 \%$ & $41,7 \%$ & $28,3 \%$ & $3,3 \%$ & $5,0 \%$ & $3,3 \%$ & $11,7 \%$ & $5,0 \%$ \\
\hline Bonita & $36,7 \%$ & $23,3 \%$ & $43,3 \%$ & $60,0 \%$ & $8,3 \%$ & $40,0 \%$ & $20,0 \%$ & $36,7 \%$ & $25,0 \%$ \\
\hline $\mathrm{N}$ bonita $\mathrm{n}$ feia & $41,7 \%$ & $33,3 \%$ & $8,3 \%$ & $6,7 \%$ & $25,0 \%$ & $36,7 \%$ & $18,3 \%$ & $38,3 \%$ & $41,7 \%$ \\
\hline Feia & $6,7 \%$ & $36,7 \%$ & $5,0 \%$ & $5,0 \%$ & $50,0 \%$ & $15,0 \%$ & $45,0 \%$ & $11,7 \%$ & $23,3 \%$ \\
\hline Muito feia & $5 \%$ & $3,3 \%$ & $1,7 \%$ & $0,0 \%$ & $13,3 \%$ & $3,3 \%$ & $13,3 \%$ & $1,7 \%$ & $5,0 \%$ \\
\hline mvo Kendall & 5,42 & 4,08 & 7,22 & 7,18 & 2,84 & 5,12 & 3,32 & 5,44 & 4,39 \\
\hline mvo K-W & 106,22 & 86,35 & 86,24 & 94,68 & 71,43 & 89,92 & 78,58 & 98,62 & 101,98 \\
\hline \multicolumn{10}{|c|}{ Não arquitetos com formação superior - 60 respondentes } \\
\hline Muito bonita & $6,7 \%$ & $3,3 \%$ & $55,0 \%$ & $38,3 \%$ & $6,7 \%$ & $8,3 \%$ & $6,7 \%$ & $10,0 \%$ & $3,3 \%$ \\
\hline Bonita & $23,3 \%$ & $30,0 \%$ & $35,0 \%$ & $43,3 \%$ & $28,3 \%$ & $45,0 \%$ & $26,7 \%$ & $25,0 \%$ & $8,3 \%$ \\
\hline $\mathrm{N}$ bonita $\mathrm{n}$ feia & $45,0 \%$ & $31,7 \%$ & $5,0 \%$ & $13,3 \%$ & $31,7 \%$ & $33,3 \%$ & $28,3 \%$ & $35,0 \%$ & $35,0 \%$ \\
\hline Feia & $18,3 \%$ & $28,3 \%$ & $5,0 \%$ & $3,3 \%$ & $25,0 \%$ & $11,7 \%$ & $25,0 \%$ & $25,0 \%$ & $36,7 \%$ \\
\hline Muito feia & $6,7 \%$ & $6,7 \%$ & $0,0 \%$ & $1,7 \%$ & $8,3 \%$ & $1,7 \%$ & $13,3 \%$ & $5,0 \%$ & $16,7 \%$ \\
\hline mvo Kendall & 4,37 & 4,28 & 7,63 & 7,09 & 4,33 & 5,47 & 4,22 & 4,66 & 2,96 \\
\hline mvo K-W & 86,67 & 92,10 & 98,82 & 97,94 & 101,74 & 99,42 & 94,37 & 81,32 & 73,84 \\
\hline \multicolumn{10}{|c|}{ Respondentes sem formação superior - 60 respondentes } \\
\hline Muito bonita & $5,0 \%$ & $3,3 \%$ & $45,0 \%$ & $25,0 \%$ & $5,0 \%$ & $10,0 \%$ & $6,7 \%$ & $10,0 \%$ & $5,0 \%$ \\
\hline Bonita & $13,3 \%$ & $21,7 \%$ & $33,3 \%$ & $41,7 \%$ & $28,3 \%$ & $25,0 \%$ & $30,0 \%$ & $36,7 \%$ & $23,3 \%$ \\
\hline $\mathrm{N}$ bonita $\mathrm{n}$ feia & $56,7 \%$ & $46,7 \%$ & $18,3 \%$ & $21,7 \%$ & $31,7 \%$ & $40,0 \%$ & $25,0 \%$ & $30,0 \%$ & $41,7 \%$ \\
\hline Feia & $18,3 \%$ & $26,7 \%$ & $3,3 \%$ & $10,0 \%$ & $23,3 \%$ & $21,7 \%$ & $31,7 \%$ & $18,3 \%$ & $11,7 \%$ \\
\hline Muito feia & $6,7 \%$ & $1,7 \%$ & $0,0 \%$ & $1,7 \%$ & $11,7 \%$ & $3,3 \%$ & $6,7 \%$ & $5,0 \%$ & $18,3 \%$ \\
\hline mvo Kendall & 4,16 & 4,35 & 7,43 & 6,53 & 4,16 & 4,82 & 4,36 & 5,11 & 4,09 \\
\hline mvo K-W & 78,61 & 93,05 & 86,43 & 78,88 & 98,32 & 82,16 & 98,55 & 91,55 & 95,68 \\
\hline
\end{tabular}

Nota: Legenda:

$\mathrm{N}$ satisfação = níveis de satisfação;

$\mathrm{N}$ bonita $\mathrm{n}$ feia = cena nem bonita nem feia;

mvo Kendall = média dos valores ordinais obtida através do teste Kendall W;

mvo K-W = média dos valores ordinais obtida através do teste Kruskal-Wallis;

a comparação entre os valores de mvo Kendall deve ser feita na horizontal, entre as cenas;

a comparação entre os valores mvo K-W deve ser feita na vertical, entre os grupos.

194 Reis, A. T. da L.; Biavatti, C. D.; Pereira, M. L. 


\begin{tabular}{|c|c|c|c|}
\hline Amostra Total (180) & Arquitetos (60) & Não arq com form. sup. (60) & Resp sem form. sup. \\
\hline \multicolumn{4}{|c|}{ Cenas mais satisfatórias } \\
\hline $\begin{array}{l}\text { Cena } 3 \text { (cena histórica de Praga } \\
\text { com ordem e estímulo) } \\
\text { Cena } 4 \text { (cena histórica de Porto } \\
\text { Alegre com ordem e estímulo) } \\
\text { Cena } 6 \text { (cena histórica de Porto } \\
\text { Alegre com ordem e pouco } \\
\text { estímulo) } \\
\text { Cena } 8 \text { (cena contemporânea } \\
\text { de Porto Alegre com ordem e } \\
\text { estímulo) }\end{array}$ & $\begin{array}{l}\text { Cena } 3 \text { (cena histórica de Praga } \\
\text { com ordem e estímulo) } \\
\text { Cena } 4 \text { (cena histórica de Porto } \\
\text { Alegre com ordem e estímulo) } \\
\text { Cena } 8 \text { (cena contemporânea } \\
\text { de Porto Alegre com ordem e } \\
\text { estímulo) } \\
\text { Cena } 1 \text { (cena histórica de } \\
\text { Florença com ordem e pouco } \\
\text { estímulo) } \\
\text { Cena } 6 \text { (cena histórica de Porto } \\
\text { Alegre com ordem e pouco } \\
\text { estímulo) }\end{array}$ & $\begin{array}{l}\text { Cena } 3 \text { (cena histórica de Praga } \\
\text { com ordem e estímulo) } \\
\text { Cena } 4 \text { (cena histórica de Porto } \\
\text { Alegre com ordem e estímulo) } \\
\text { Cena } 6 \text { (cena histórica de Porto } \\
\text { Alegre com ordem e pouco } \\
\text { estímulo) }\end{array}$ & $\begin{array}{l}\text { Cena } 3 \text { (cena histórica } \\
\text { de Praga com ordem e } \\
\text { estímulo) } \\
\text { Cena } 4 \text { (cena histórica } \\
\text { de Porto Alegre com } \\
\text { ordem e estímulo) } \\
\text { Cena } 8 \text { (cena } \\
\text { contemporânea de Porto } \\
\text { Alegre com ordem e } \\
\text { estímulo) }\end{array}$ \\
\hline \multicolumn{4}{|c|}{ Cenas mais insatisfatórias } \\
\hline $\begin{array}{l}\text { Cena } 5 \text { (cena histórica de Porto } \\
\text { Alegre com desordem) } \\
\text { Cena } 9 \text { (cena contemporânea } \\
\text { de Porto Alegre com ordem e } \\
\text { pouco estímulo) } \\
\text { Cena } 7 \text { (cena contemporânea } \\
\text { de Porto Alegre com desordem) }\end{array}$ & $\begin{array}{l}\text { Cena } 5 \text { (cena histórica de Porto } \\
\text { Alegre com desordem) } \\
\text { Cena } 7 \text { (cena contemporânea } \\
\text { de Porto Alegre com desordem) } \\
\text { Cena } 2 \text { (cena histórica de } \\
\text { Florença com desordem) }\end{array}$ & $\begin{array}{l}\text { Cena } 9 \text { (cena contemporânea } \\
\text { de porto Alegre com ordem e } \\
\text { pouco estímulo) }\end{array}$ & $\begin{array}{l}\text { Nenhuma cena possui } \\
\text { porcentagem de } \\
\text { respondentes } \\
\text { insatisfeitos visivelmente } \\
\text { maior que a de satisfeitos }\end{array}$ \\
\hline
\end{tabular}

Quadro 1 - Cenas mais satisfatórias e insatisfatórias esteticamente

Nota: Legenda:

Não arq com form. sup. = não arquitetos com formação superior;

Resp. sem form. sup.= respondentes sem formação superior;

as cenas mais satisfatórias foram organizadas a partir da mais satisfatória e possuem a porcentagem de respondentes satisfeitos visivelmente maior que a de insatisfeitos;

as cenas mais insatisfatórias foram organizadas a partir da mais insatisfatória e possuem a porcentagem de respondentes insatisfeitos visivelmente maior que a de satisfeitos.

Esses resultados indicam o impacto positivo da ideia de ordem e estímulo visual na avaliação estética dos respondentes (Tabela 1 e Quadro 1). Salienta-se também que as cenas 3 e 4 (caracterizadas pela ideia de ordem e estímulo visual) foram as duas cenas mais satisfatórias esteticamente para os grupos dos arquitetos, não arquitetos com curso superior e respondentes sem formação superior (Tabela 1 e Quadro 1). Ainda, a cena 8 (ordem e estímulo visual) foi a terceira mais satisfatória para os arquitetos e para aqueles sem formação universitária (Tabela 1 e Quadro 1).

As cenas consideradas mais insatisfatórias esteticamente para a amostra total de 180 respondentes são as seguintes (Tabela 1 e Quadro 1):
(a) cena 5: Figura 8;
(b) cena 9: Figura 12; e
(c) a cena 7: Figura 10

Ao contrário das cenas 3 e 4, a cena 5 (Figura 8 cena de Porto Alegre com desordem histórica), a mais insatisfatória, foi julgada feia ou muito feia por $43,9 \%$ da amostra total de respondentes e bonita ou muito bonita por apenas $26,7 \%$ deles. A cena 9 (Figura 12 - cena contemporânea de Porto Alegre com ordem e pouco estímulo) foi avaliada como insatisfatória por $37,2 \%$ do total de respondentes e como satisfatória por somente
23,3\% dos 180 respondentes. A cena 7 (Figura 10 cena contemporânea de Porto Alegre com desordem) foi avaliada como feia ou muito feia por $45 \%$ e como bonita ou muito bonita por $30,2 \%$ da amostra total de 180 respondentes (Tabela 1 e Quadro 1).

Esses resultados mostram que a falta de organização tende a gerar respostas estéticas negativas e que a ideia de ordem pode não ser suficiente para produzir respostas estéticas positivas se o estímulo for muito pequeno, caracterizando um conjunto arquitetônico que pode ser percebido como monótono. O impacto negativo da ideia de desordem fica corroborado pela avaliação realizada pelo grupo de arquitetos, em que as três cenas mais insatisfatórias esteticamente são caracterizadas pela desordem (Tabela 1 e Quadro 1). Por outro lado, o impacto negativo que a ideia de ordem com pouco estímulo pode gerar fica evidenciado na amostra de não arquitetos com formação universitária.

$\mathrm{O}$ ordenamento das cenas pelos respondentes, da mais para a menos preferida quanto à aparência, reproduz os resultados anteriores relativos à avaliação individual das cenas, enfatizando:

(a) o efeito estético positivo e a consequente preferência estética por cenas caracterizadas pela ideia de ordem e estímulo (cenas 3 e 4); e 
(b) o impacto estético negativo da ideia de desordem (cenas 7 e 5) e a possibilidade da ideia de ordem com pouco estímulo (cena 9) também provocar uma reação estética negativa, resultando em cenas não ou pouco preferidas (Tabela 2).

(c) A ordem de preferência das cenas para os arquitetos reflete suas avaliações individuais das cenas, com as cenas mais preferidas $(3,4$ e 8$)$ confirmando o efeito positivo da ideia de ordem e estímulo visual, e as cenas menos preferidas $(5,7$, $9,2)$ ratificando o impacto negativo da ideia de desordem (cenas 5, 7 e 2) e a possibilidade da ideia de ordem com pouco estímulo (cena 9) também provocar uma reação estética negativa.

A ordem de preferências das cenas para os não arquitetos com curso superior referenda suas avaliações individuais das cenas, com:

(a) as cenas mais preferidas (3, 4 e 6$)$ reforçando o efeito positivo da ideia de ordem e estímulo visual (cenas 3 e 4 ) e a possibilidade da ideia de ordem com pouco estímulo também gerar impacto estético satisfatório; e

(b) as cenas menos preferidas (9 e 7) sustentam a possibilidade da ideia de ordem com pouco estímulo (cena 9) provocar uma reação estética negativa assim como o impacto negativo da ideia de desordem (cena 7).

Para este grupo, contudo, as outras duas cenas com desordem (5 e 2) foram preferidas à cena 8 (cena contemporânea de Porto Alegre com ordem e estímulo). Para os respondentes sem curso superior, as cenas mais preferidas (3, 4 e 2) indicam a confirmação do efeito positivo das cenas 3 e 4 (ordem com estímulo) embora a cena 2 (cena histórica de Florença com desordem) tenha sido preferida à cena 8 (cena contemporânea de Porto
Alegre com ordem e estímulo), cena esta avaliada como a terceira mais satisfatória (Tabela $1 \mathrm{e}$ Quadro 1). Para este grupo, as cenas menos preferidas (9, 1 e 7) incluem duas cenas com ordem e pouco estímulo ( 9 e 1) e uma com desordem (7), sustentando que, além da ideia de desordem, a ideia de ordem com pouco estímulo pode não ser esteticamente atraente. Assim, considerando os resultados provenientes das avaliações individuais das cenas e da preferência delas, fica evidenciado que cenas percebidas como esteticamente positivas estão essencialmente associadas à ideia de ordem com estímulo, seguidas pela ideia de ordem com pouco estímulo; e que cenas percebidas como esteticamente negativas estão associadas à ideia de desordem e à ideia de ordem com pouco estímulo, mostrando que esta também pode gerar impacto negativo.

Esses resultados ainda se explicam pelas razões mencionadas pelos respondentes para justificar a preferência pelas cenas (Tabela 3). Essas razões corroboram a importância da ideia de ordem (similaridade entre as formas e as alturas) como condição necessária para uma percepção estética positiva, assim como uma percepção estética negativa é fortemente explicada pela ideia de desordem (diferenças entre formas e alturas) para os arquitetos e para os respondentes sem formação universitária. Por outro lado, para os não arquitetos com formação universitária, a "similaridade entre as formas" foi um pouco mais mencionada do que a "diferença entre as formas" como razão para a cena menos preferida (Tabela 3), explicando porque para este grupo a cena 9 (cena contemporânea de Porto Alegre com ordem e pouco estímulo) foi avaliada como a mais insatisfatória, além de ser a menos preferida (Tabelas 1 e 2 e Quadro 1).

Tabela 2 - Ordem de preferência das cenas quanto à aparência

\begin{tabular}{|c|c|c|c|c|c|c|c|c|c|c|}
\hline \multicolumn{2}{|c|}{ Total } & \multicolumn{3}{|c|}{ Arquitetos } & \multicolumn{3}{|c|}{ Não arquitetos com formação } & \multicolumn{3}{|c|}{ Resp sem formação } \\
\hline Cena & mv K & Cena & mv K & mvK-W & Cena & mv K & mvK-W & Cena & mv K & mvK-W \\
\hline $3(1401)$ & 7,78 & $3(459)$ & 7,65 & 83,15 & $3(477)$ & 7,95 & 96,08 & $3(465)$ & 7,75 & 92,27 \\
\hline $4(1284)$ & 7,13 & $4(429)$ & 7,15 & 92,28 & $4(449)$ & 7,48 & 99,53 & $4(406)$ & 6,77 & 79,69 \\
\hline $6(898)$ & 4,99 & $8(329)$ & 5,48 & 108,62 & $6(311)$ & 5,18 & 95,02 & $2(315)$ & 5,25 & 103,83 \\
\hline $8(846)$ & 4,70 & $1(301)$ & 5,02 & 102,47 & $5(284)$ & 4,73 & 100,91 & $5(302)$ & 5,03 & 107,52 \\
\hline $2(842)$ & 4,68 & $6(293)$ & 4,88 & 88,51 & $2(272)$ & 4,53 & 87,56 & $6(294)$ & 4,90 & 87,98 \\
\hline $1(809)$ & 4,49 & $2(255)$ & 4,25 & 80,11 & $1(266)$ & 4,43 & 89,49 & $8(261)$ & 4,35 & 82,48 \\
\hline $5(768)$ & 4,27 & $9(243)$ & 4,05 & 110,37 & $8(256)$ & 4,27 & 80,41 & $7(242)$ & 4,03 & 95,95 \\
\hline 7 (686) & 3,81 & $7(209)$ & 3,48 & 81,76 & $7(235)$ & 3,92 & 93,79 & $1(242)$ & 4,03 & 79,54 \\
\hline $9(566)$ & 3,14 & $5(182)$ & 3,03 & 63,08 & $9(150)$ & 2,50 & 75,17 & $9(173)$ & 2,88 & 85,97 \\
\hline
\end{tabular}

Nota: Legenda:

Resp sem formação = respondentes sem formação superior;

$\mathrm{mv} \mathrm{K}$ - média dos valores ordinais obtida através do teste Kendall W;

$\mathrm{mv} \mathrm{K}-\mathrm{W}$ - média dos valores ordinais obtida através do teste Kruskal-Wallis;

$c(p)$ - c: cena em avaliação e p: pontuação recebida. 
Tabela 3 - Principais razões que justificam a preferência

\begin{tabular}{|c|c|c|c|c|c|c|}
\hline Razões & Arquitetos & $\mathrm{N}$ arq c f sup & Resp s f sup & Total & Sig & Phi \\
\hline \multicolumn{7}{|c|}{ Cena mais preferida } \\
\hline $\begin{array}{l}\text { Similaridade entre as } \\
\text { formas }\end{array}$ & $65,0 \%$ & $51,7 \%$ & $40,0 \%$ & $52,2 \%$ & 0,023 & 0,205 \\
\hline Similaridade entre as alturas & $68,3 \%$ & $45,0 \%$ & $38,3 \%$ & $50,6 \%$ & 0,003 & 0,257 \\
\hline Similaridade entre as cores & $25,0 \%$ & $26,7 \%$ & $26,7 \%$ & $26,1 \%$ & 0,972 & 0,018 \\
\hline Diferença entre as cores & $15,0 \%$ & $28,3 \%$ & $26,7 \%$ & $23,3 \%$ & 0,170 & 0,140 \\
\hline Diferença entre as alturas & $10,0 \%$ & $10,0 \%$ & $13,3 \%$ & $11,1 \%$ & 0,799 & 0,050 \\
\hline \multicolumn{7}{|c|}{ Cena menos preferida } \\
\hline Diferença entre as formas & $48,3 \%$ & $36,7 \%$ & $28,3 \%$ & $37,8 \%$ & 0,076 & 0,169 \\
\hline Diferença entre as alturas & $50,0 \%$ & $25,0 \%$ & $26,7 \%$ & $33,9 \%$ & 0,005 & 0,241 \\
\hline $\begin{array}{l}\text { Similaridade entre as } \\
\text { formas }\end{array}$ & $30,0 \%$ & $41,7 \%$ & $15,0 \%$ & $28,9 \%$ & 0,005 & 0,241 \\
\hline Similaridade entre as cores & $21,7 \%$ & $25,0 \%$ & $13,3 \%$ & $20,0 \%$ & 0,258 & 0,123 \\
\hline Similaridade entre as alturas & $21,7 \%$ & $16,7 \%$ & $16,7 \%$ & $18,3 \%$ & 0,716 & 0,061 \\
\hline Diferença entre as cores & $13,3 \%$ & $15,0 \%$ & $21,7 \%$ & $16,7 \%$ & 0,432 & 0,097 \\
\hline Monotonia da cena & $11,7 \%$ & $8,3 \%$ & $6,7 \%$ & $8,9 \%$ & 0,619 & 0,073 \\
\hline
\end{tabular}

Nota: Legenda:

$\mathrm{N}$ arq $\mathrm{c}$ f sup = não arquiteto com formação superior;

Resp s f sup = respondente sem formação superior;

os valores de sig e phi foram obtidos através de tabulação cruzada.

\section{Impacto da estética formal e da estética simbólica}

O impacto da estética formal e da estética simbólica é considerado através dos resultados provenientes das avaliações das nove cenas com diferentes níveis de familiaridade e valor histórico, pelo total dos 180 respondentes e pelos respondentes de cada grupo, e da identificação de diferenças entre tais avaliações através do teste estatístico Kendall W.

Os resultados acima apresentados indicam que um maior nível da familiaridade com a cena não foi determinante para sua avaliação positiva, considerando-se que a cena 3 (cena histórica de Praga com ordem e estímulo), cena menos familiar do que as de Porto Alegre, foi avaliada como a cena mais satisfatória, assim como foi a cena preferida pelo total dos 180 respondentes e por cada um dos três grupos de respondentes (Tabelas 1 e 2 e Quadro 1). Ainda, a cena 5 (cena com desordem histórica de Porto Alegre), avaliada como a mais insatisfatória esteticamente pelo total dos 180 respondentes e pelo grupo dos arquitetos, foi a cena menos preferida para este grupo (Tabelas 1 e 2 e Quadro 1).

Contudo, para o total dos 180 respondentes, observa-se que (Tabela 4) as três cenas mais preferidas quanto à aparência (cenas 3,4 e 6 Tabela 2) possuem um percentual bem maior de respondentes que as classificaram como conhecidas ou familiares, embora a cena 3 seja a cena histórica de Praga; as demais cenas possuem um percentual maior de respondentes que as consideraram como desconhecidas ou não familiares, embora as cenas contemporâneas de Porto Alegre (7, 8 e 9), assim como a cena histórica de Porto Alegre com desordem (5), sejam compostas de edificações dessa cidade; sempre que houve uma relação estatisticamente significativa (teste Mann-Whitney; em seis das nove cenas) entre familiaridade e preferência, aqueles que classificaram a cena como familiar lhe deram maior preferência (Tabela 4). Para os três grupos, considerados individualmente, observa-se que (Tabela 4), embora as duas cenas mais preferidas quanto à aparência (cenas 3 e 4 - Tabela 2) possuam um percentual maior de respondentes que as classificaram como conhecidas ou familiares, o oposto acontece com a terceira cena mais preferida pelos arquitetos (cena 8) e com a terceira cena mais preferida pelos respondentes sem formação universitária (cena 2). Enquanto as cenas 4 (cena histórica de Porto Alegre com ordem e estímulo) e 6 (cena histórica de Porto Alegre com ordem e pouco estímulo) foram classificadas como familiares pela maioria dos respondentes de cada grupo, o oposto ocorreu com as demais cenas de Porto Alegre (5, 7, 8 e 9). A maioria dos arquitetos classificaram as cenas 1 e 2 (Florença) como familiares, ocorrendo o oposto para os outros dois grupos, com diferenças expressivas para o grupo dos respondentes sem formação universitária. A cena 3 (Praga) foi considerada familiar pela clara maioria nos três grupos. Sempre que houve uma relação estatisticamente significativa (teste MannWhitney) entre familiaridade e preferência, embora em poucas cenas, aqueles que classificaram a cena 
como familiar lhe deram maior preferência (Tabela 4).

Logo, o fato de a cena ser composta de edificações de Porto Alegre não determinou que ela fosse percebida como familiar, assim como o fato de a cena ser composta de edificações de Florença ou Praga não determinou que ela fosse percebida como não familiar. As explicações para tais resultados parecem estar relacionadas ao fato de que as cenas foram montadas e não reproduzem cenas existentes, possibilitando a diminuição da familiaridade, e que a divulgação de imagens de cidades como Florença e Praga (p.ex., através da televisão, internet e revistas), além de reconhecimento in loco, potencializou o aumento da familiaridade, embora tenham sido encontradas algumas diferenças entre os grupos, provavelmente devido às diferenças entre os níveis e tipos de formação acadêmica. Embora para a maioria das cenas, principalmente para os grupos dos não arquitetos com formação universitária e aqueles sem formação universitária, não exista diferença estatisticamente significativa quanto à preferência pela cena entre aqueles que a classificaram como familiar e aqueles que a classificaram como não familiar, quando tal diferença foi encontrada a cena foi mais preferida por aqueles que a consideraram familiar (Tabela 4).

Contudo, considerando as informações obtidas através das entrevistas (Tabela 5), observa-se que a maioria, seja do total dos 180 entrevistados, seja dos 60 entrevistados em cada um dos três grupos, explicou que a avaliação da cena não foi afetada pelo fato de ela ser percebida ou não como familiar. Como mencionado por alguns respondentes, "a questão da qualidade estética está diretamente relacionada à harmonia da construção, principalmente à composição e identidade formal"'. $\mathrm{Ou}$, ainda, "a cena preferida, embora muito conhecida, possui qualidades inegáveis, tendo unidade sem monotonia e relações claras entre as edificações, não apenas justaposições". Por outro lado, a quantidade daqueles com opinião oposta não pode ser desprezada, seja no total, seja em cada um dos três grupos (Tabela 5).

Tabela 4 - Familiaridade das cenas e influência na ordem de preferência

\begin{tabular}{|c|c|c|c|c|c|c|c|c|c|}
\hline Familiarid & $\begin{array}{c}\text { Cena } 1 \\
\text { Fig. } 4\end{array}$ & $\begin{array}{c}\text { Cena } 2 \\
\text { Fig. } 5\end{array}$ & $\begin{array}{c}\text { Cena } 3 \\
\text { Fig. } 6\end{array}$ & $\begin{array}{c}\text { Cena } 4 \\
\text { Fig. } 7\end{array}$ & $\begin{array}{c}\text { Cena } 5 \\
\text { Fig. } 8\end{array}$ & $\begin{array}{c}\text { Cena } 6 \\
\text { Fig. } 9\end{array}$ & $\begin{array}{l}\text { Cena } 7 \\
\text { Fig. } 10\end{array}$ & $\begin{array}{l}\text { Cena } 8 \\
\text { Fig. } 11\end{array}$ & $\begin{array}{l}\text { Cena } 9 \\
\text { Fig. } 12\end{array}$ \\
\hline & $\begin{array}{c}\%(\mathrm{mM}- \\
\mathrm{W})\end{array}$ & $\begin{array}{c}\%(\mathrm{mM}- \\
\mathrm{W})\end{array}$ & $\%(\mathrm{mM}-\mathrm{W})$ & $\%(\mathrm{mM}-\mathrm{W})$ & $\%(\mathbf{m M}-\mathbf{W})$ & $\begin{array}{c}\%(\mathrm{mM}- \\
\mathrm{W})\end{array}$ & $\begin{array}{c}\% \text { (mM- } \\
\text { W) }\end{array}$ & $\begin{array}{c}\% \text { (mM- } \\
\text { W) }\end{array}$ & $\begin{array}{c}\% \text { (mM- } \\
\text { W) }\end{array}$ \\
\hline \multicolumn{10}{|c|}{ Amostra total -180 respondentes } \\
\hline Conh/fam & $\begin{array}{c}47,2(106,86 \\
)\end{array}$ & $39,4(91,37)$ & $69,4(92,86)$ & $71,7(97,12)$ & $\begin{array}{c}42,2(100,34 \\
)\end{array}$ & $62,2(97,19)$ & $27,2(90,41)$ & $\begin{array}{c}46,7(101,45 \\
)\end{array}$ & $\begin{array}{c}31,1(105,83 \\
) \\
\end{array}$ \\
\hline $\begin{array}{l}\text { Desc/n } \\
\text { fam }\end{array}$ & $52,8(78,27)$ & $60,6(89,93)$ & $30,6(85,15)$ & $28,3(73,75)$ & $57,8(83,31)$ & $37,8(79,49)$ & $72,8(90,53)$ & $53,3(80,92)$ & $68,9(83,58)$ \\
\hline Sig & 0,000 & No sig & No sig & 0,005 & 0,029 & 0,025 & No sig & 0,008 & 0,007 \\
\hline $\begin{array}{l}\text { Posição } \\
\text { o.p. }\end{array}$ & $6^{\circ}$ & $5^{\circ}$ & $1^{\circ}$ & $2^{\circ}$ & $7^{\circ}$ & $3^{\circ}$ & $8^{\circ}$ & $4^{\circ}$ & $9^{\circ}$ \\
\hline \multicolumn{10}{|c|}{ Arquitetos -60 respondentes } \\
\hline Conh/fam & $66,7(34,45)$ & $51,7(35,27)$ & $71,6(33,19)$ & $83,3(31,82)$ & $45,0(37,72)$ & $70,0(32,19)$ & $35,0(29,95)$ & $43,3(30,35)$ & $41,7(35,20)$ \\
\hline $\begin{array}{l}\text { Desc/n } \\
\text { fam }\end{array}$ & $33,3(22,60)$ & $48,3(25,40)$ & $28,3(23,71)$ & $16,7(23,90)$ & $55,0(24,59)$ & $30,0(26,56)$ & $65,0(30,79)$ & $56,7(30,62)$ & $58,3(27,14)$ \\
\hline Sig & 0,012 & 0,027 & 0,046 & No sig & 0,003 & No sig & No sig & No sig & No sig \\
\hline $\begin{array}{l}\text { Posição } \\
\text { o.p. }\end{array}$ & $4^{\circ}$ & $6^{\circ}$ & $1^{\circ}$ & $2^{\circ}$ & $9^{\circ}$ & $5^{\circ}$ & $8^{\circ}$ & $3^{\circ}$ & $7^{\circ}$ \\
\hline \multicolumn{10}{|c|}{ Não arquitetos com formação superior - 60 respondentes } \\
\hline Conh/fam & $41,7(39,96)$ & $48,3(27,40)$ & $68,3(29,37)$ & $75,0(31,74)$ & $48,3(31,62)$ & $65,0(34,29)$ & $25,0(25,73)$ & $48,3(33,74)$ & $35,0(34,95)$ \\
\hline $\begin{array}{l}\text { Desc/n } \\
\text { fam }\end{array}$ & $58,3(25,89)$ & $51,7(33,40)$ & $31,7(32,95)$ & $25,0(26,77)$ & $51,7(29,45)$ & $35,0(23,45)$ & $75,0(32,09)$ & $51,7(27,47)$ & $65,0(28,10)$ \\
\hline Sig & 0,014 & No sig & No sig & No sig & No sig & 0,020 & No sig & No sig & No sig \\
\hline $\begin{array}{l}\text { Posição } \\
\text { o.p. }\end{array}$ & $6^{\circ}$ & $5^{\circ}$ & $1^{\circ}$ & $2^{\circ}$ & $4^{\circ}$ & $3^{\circ}$ & $8^{\circ}$ & $7^{\circ}$ & $9^{\circ}$ \\
\hline \multicolumn{10}{|c|}{ Respondentes sem formação superior - 60 respondentes } \\
\hline Conh/fam & $20,0(32,63)$ & $18,3(31,50)$ & $68,3(31,28)$ & $56,7(33,63)$ & $33,3(35,88)$ & $51,7(31,03)$ & $21,7(36,77)$ & $48,3(38,48)$ & $16,7(34,20)$ \\
\hline Desc/n fam & $80,0(29,97)$ & $81,7(30,28)$ & $31,7(28,82)$ & $43,3(26,40)$ & $66,7(27,81)$ & $48,3(29,93)$ & $78,3(28,77)$ & $51,7(23,03)$ & $83,3(29,76)$ \\
\hline Sig & No sig & No sig & No sig & No sig & No sig & No sig & No sig & 0,001 & No sig \\
\hline Posição o.p. & $8^{\circ}$ & $3^{\circ}$ & $1^{\circ}$ & $2^{\circ}$ & $4^{\circ}$ & $5^{\circ}$ & $7^{\circ}$ & $6^{\circ}$ & $9^{\circ}$ \\
\hline
\end{tabular}

Nota: Legenda:

familiarid = familiaridade;

$\%(m M-W)=$ percentual sobre amostra total e individual de respondentes que classificou a cena como familiar ou não familiar (média obtida através do teste Mann-Whitney entre as variáveis preferência e familiaridade da cena; maior valor = maior preferência);

conh $/$ fam = cena conhecida ou familiar;

$\mathrm{desc} / \mathrm{n}$ fam = cena desconhecida ou não familiar;

sig = valor de significância obtido através do teste Mann-Whitney;

posição o.p. = posição ocupada pela cena na ordem de preferência quanto à aparência (Tabela 2).

198 Reis, A. T. da L.; Biavatti, C. D.; Pereira, M. L. 
Tabela 5 - Entrevistados afetados e não afetados pela familiaridade e pelo valor histórico

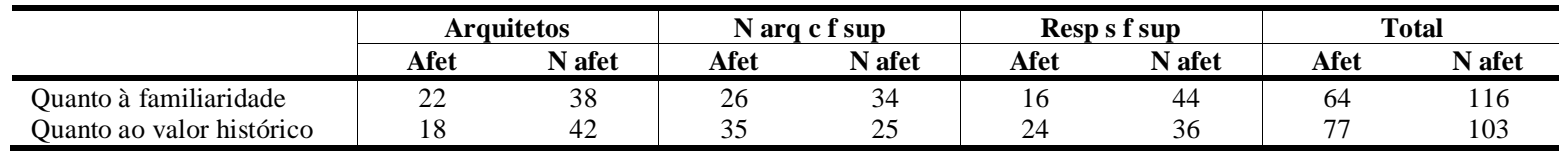

Nota: Tabela efetuada com base nas respostas das entrevistas.

Legenda:

$\mathrm{N}$ arq c f sup = não arquitetos com formação superior;

Resp s f sup = respondentes sem formação superior;

$\mathrm{N}$ afet $=$ respondentes não afetados por familiaridade e/ou valor histórico

Considerando a amostra total de entrevistados que se disseram afetados pela familiaridade das cenas em suas avaliações (64 - Tabelas 5 e 6), o motivo mais mencionado para explicar tal efeito foi "a cena remete a lembranças", sejam estas referentes a viagens, fotografias ou filmes, lembranças que os levaram a reconhecer e a simpatizar com a cena. Essa também foi a principal justificativa para não arquitetos com formação e respondentes sem formação universitária, e a segunda mais mencionada pelos arquitetos (Tabela 6). Para uma entrevistada, graduada em ciências biológicas, algumas cenas "fizeram recordar a qualidade de vida que se tem em cidades do interior". A “a vivência urbana" foi a justificativa mais mencionada pelos arquitetos entrevistados para explicar a interferência da familiaridade na preferência por uma cena (Tabela 6). Conforme descrito por um dos arquitetos entrevistados, "cenas semelhantes são, muitas vezes, vivenciadas no centro e em alguns bairros de Porto Alegre, como Cidade Baixa e Independência".

Outros aspectos mais mencionados pelos entrevistados para explicar a influência da familiaridade na avaliação de uma cena incluem a "propensão do indivíduo em gostar do que está acostumado" e a "associação com cenas europeias" (Tabela 6). Segundo um entrevistado, "o fato de o ser humano aceitar melhor a imagem com a qual está familiarizado e reagir natural e contrariamente ao novo ou a mudanças" foi determinante para a avaliação das cenas. No tocante às associações das cenas avaliadas com cenas europeias (que seriam então familiares para alguns), alguns entrevistados reconheceram as cenas históricas montadas a partir de fotografias de edificações de Florença (cenas 1 e 2) e Praga (cena 3), enquanto outros associaram a essas três cenas, bem como a cenas de Porto Alegre, ambientes urbanos de outros países situados na Europa, como Bélgica, Holanda, França e Espanha. Nesse caso, as características formais das cenas podem ter afetado as avaliações, e não propriamente a familiaridade com elas. Sintetizando, os resultados indicam que, embora a familiaridade com uma cena não tenha afetado sua avaliação e preferência por parte da maioria dos participantes na investigação, alguns deles tiveram suas avaliações e preferências afetadas.

Com relação ao valor histórico, os resultados indicam que sua existência não determinou uma avaliação mais positiva ou maior preferência pela cena, conforme demonstrado em relação à cena 5 (cena com desordem histórica de Porto Alegre) (Tabelas 1 e 2 e Quadro 1). Ainda, pode-se argumentar que a percepção estética da cena 3 (cena histórica de Praga com ordem e estímulo) como a mais positiva não é explicada pelo valor histórico das edificações, já que os respondentes teriam menor conhecimento da história de tais edificações do que daquelas em Porto Alegre que compõem a cena 5. Ainda, a cena 8 (cena contemporânea de Porto Alegre com ordem e estímulo) foi avaliada como esteticamente mais satisfatória do que as cenas 5, 2 (cena histórica de Florença com desordem) e 1 (cena histórica de Florença com ordem e pouco estímulo) pelo total dos 180 respondentes, pelo grupo dos arquitetos, dos não arquitetos com formação universitária e pelo grupo dos respondentes sem formação universitária (Tabela 1 e Quadro 1). A cena 8 também foi preferida em relação a essas três cenas pelo total dos 180 respondentes e pelo grupo dos arquitetos (Tabela 2). 
Tabela 6 - Justificativas relacionadas à familiaridade e ao valor histórico

\begin{tabular}{|c|c|c|c|c|}
\hline \multirow{2}{*}{$\begin{array}{l}\text { Justificativas dos entrevistados afetados pela } \\
\text { familiaridade e pelo valor histórico }\end{array}$} & Arquitetos & $\mathbf{N}$ arq c f sup & Resp s f sup & Total \\
\hline & n.a $(\%)$ & n.a $(\%)$ & n.a $(\%)$ & n.a $(\%)$ \\
\hline \multicolumn{5}{|c|}{ Justificativas relacionadas à familiaridade } \\
\hline Justificativas daqueles afetados pela familiaridade & $22(100)$ & $26(100)$ & $16(100)$ & $64(100)$ \\
\hline A cena remete a lembranças & $4(18,18)$ & $6(23,07)$ & $5(31,25)$ & $15(23,43)$ \\
\hline Propensão a gostar do que está acostumado & $4(18,18)$ & $3(11,53)$ & $1(6,25)$ & $8(12,50)$ \\
\hline Associação com cenas europeias & $1(4,54)$ & $3(11,53)$ & $2(12,50)$ & $6(9,37)$ \\
\hline Preferência devido à vivência urbana & $5(22,72)$ & $0(00,00)$ & $0(00,00)$ & $5(7,81)$ \\
\hline Cena familiar gera sensação de conforto & $0(00,00)$ & $3(11,53)$ & $0(00,00)$ & $3(4,68)$ \\
\hline Influência de ideia preconcebida de cenas familiares & $1(4,54)$ & $1(3,84)$ & $0(00,00)$ & $2(3,12)$ \\
\hline Experiência espacial contribui para noção estética & $2(9,09)$ & $0(00,00)$ & $0(00,00)$ & $2(3,12)$ \\
\hline A cena instiga a imaginação do respondente & $0(00,00)$ & $2(7,69)$ & $0(00,00)$ & $2(3,12)$ \\
\hline $\begin{array}{l}\text { O respondente associou a cena preferida ao conjunto de } \\
\text { edificações da UFRGS }\end{array}$ & $0(00,00)$ & $0(00,00)$ & $2(12,50)$ & $2(3,12)$ \\
\hline Relação entre lembranças e estética & $1(4,54)$ & $0(00,00)$ & $0(00,00)$ & $1(1,56)$ \\
\hline Conhecimento referente à história dos edifícios & $1(4,54)$ & $0(00,00)$ & $0(00,00)$ & $1(1,56)$ \\
\hline $\begin{array}{l}\text { Familiaridade somada a aspectos compositivos tornam a } \\
\text { cena simpática }\end{array}$ & $0(00,00)$ & $1(3,84)$ & $0(00,00)$ & $1(1,56)$ \\
\hline Cenas familiares alteram a noção de beleza & $0(00,00)$ & $1(3,84)$ & $0(00,00)$ & $1(1,56)$ \\
\hline $\begin{array}{l}\text { A observação repetida de cenas familiares causa um } \\
\text { refinamento da percepção }\end{array}$ & $0(00,00)$ & $1(3,84)$ & $0(00,00)$ & $1(1,56)$ \\
\hline A educação recebida torna o valor histórico inquestionável & $0(00,00)$ & $0(00,00)$ & $1(6,25)$ & $1(1,56)$ \\
\hline Preferência devido a aspectos compositivos & $0(00,00)$ & $0(00,00)$ & $1(6,25)$ & $1(1,56)$ \\
\hline A cena faz parte do cotidiano do respondente & $1(4,54)$ & $0(00,00)$ & $0(00,00)$ & $1(1,56)$ \\
\hline $\begin{array}{l}\text { Cenas familiares remetem à noção de pertencimento do } \\
\text { respondente ao local }\end{array}$ & $1(4,54)$ & $0(00,00)$ & $0(00,00)$ & $1(1,56)$ \\
\hline As outras cenas pareciam incompletas & $1(4,54)$ & $0(00,00)$ & $0(00,00)$ & $1(1,56)$ \\
\hline A cena é um referencial & $1(4,54)$ & $0(00,00)$ & $0(00,00)$ & $1(1,56)$ \\
\hline \multicolumn{5}{|c|}{ Justificativas relacionadas ao valor histórico } \\
\hline Justificativas daqueles afetados pelo valor histórico & $18(100)$ & $35(100)$ & $24(100)$ & $77(100)$ \\
\hline Preferência devido a aspectos compositivos & $1(5,55)$ & $8(22,85)$ & $9(37,50)$ & $18(23,37)$ \\
\hline A cena remete a lembranças & $3(16,66)$ & $1(2,85)$ & $0(00,00)$ & $4(5,19)$ \\
\hline Propensão a gostar do que está acostumado & $1(5,55)$ & $2(5,71)$ & $0(00,00)$ & $3(3,89)$ \\
\hline A cena representa a memória local & $0(00,00)$ & $3(8,57)$ & $0(00,00)$ & $3(3,89)$ \\
\hline O respondente agrega prestígio a cenas antigas & $1(5,55)$ & $2(5,71)$ & $0(00,00)$ & $3(3,89)$ \\
\hline A cena possui valor cultural & $1(5,55)$ & $0(00,00)$ & $1(4,16)$ & $2(2,59)$ \\
\hline $\begin{array}{l}\text { Cenas históricas remetem à noção de pertencimento do } \\
\text { respondente ao local }\end{array}$ & $0(00,00)$ & $2(5,71)$ & $0(00,00)$ & $2(2,59)$ \\
\hline Preferência devido à vivência urbana & $2(11,11)$ & $0(00,00)$ & $0(00,00)$ & $2(2,59)$ \\
\hline A cena possui identidade & $0(00,00)$ & $2(5,71)$ & $0(00,00)$ & $2(2,59)$ \\
\hline O respondente possui ligação afetiva com a cena & $0(00,00)$ & $2(5,71)$ & $0(00,00)$ & $2(2,59)$ \\
\hline A educação recebida torna o valor histórico inquestionável & $0(00,00)$ & $1(2,85)$ & $1(4,16)$ & $2(2,59)$ \\
\hline A cena é parte do cotidiano urbano há gerações & $1(5,55)$ & $0(00,00)$ & $1(4,16)$ & $2(2,59)$ \\
\hline Afetou negativamente & $0(00,00)$ & $1(2,85)$ & $1(4,16)$ & $2(2,59)$ \\
\hline O estado de conservação é determinante & $0(00,00)$ & $2(5,71)$ & $0(00,00)$ & $2(2,59)$ \\
\hline A cena representa a preservação do patrimônio histórico & $0(00,00)$ & $1(2,85)$ & $0(00,00)$ & $1(1,29)$ \\
\hline Conhecimento referente à história dos edifícios & $1(5,55)$ & $0(00,00)$ & $0(00,00)$ & $1(1,29)$ \\
\hline O contexto histórico valoriza a cena & $0(00,00)$ & $1(2,85)$ & $0(00,00)$ & $1(1,29)$ \\
\hline Importância da cena para o contexto urbano & $1(5,55)$ & $(00,00)$ & $0(00,00)$ & $1(1,29)$ \\
\hline A cena representa a estética de uma época & $0(00,00)$ & $1(2,85)$ & $0(00,00)$ & $1(1,29)$ \\
\hline Cenas históricas fazem recordar a história & $1(5,55)$ & $0(00,00)$ & $0(00,00)$ & $1(1,29)$ \\
\hline A cena instiga a imaginação & $0(00,00)$ & $1(2,85)$ & $0(00,00)$ & $1(1,29)$ \\
\hline Cenas históricas remetem à noção de humanização & $0(00,00)$ & $1(2,85)$ & $0(00,00)$ & $1(1,29)$ \\
\hline A cena foi associada a local de função excepcional & $0(00,00)$ & $0(00,00)$ & $1(4,16)$ & $1(1,29)$ \\
\hline Cenas antigas atraem turismo e emprego & $0(00,00)$ & $0(00,00)$ & $1(4,16)$ & $1(1,29)$ \\
\hline A cena remete a outra época & $0(00,00)$ & $0(00,00)$ & $1(4,16)$ & $1(1,29)$ \\
\hline Cada cena antiga carrega uma história & $0(00,00)$ & $0(00,00)$ & $1(4,16)$ & $1(1,29)$ \\
\hline Cenas contemporâneas são monótonas & $0(00,00)$ & $1(2,85)$ & $0(00,00)$ & $1(1,29)$ \\
\hline Associação com cenas europeias & $1(5,55)$ & $0(00,00)$ & $0(00,00)$ & $1(1,29)$ \\
\hline
\end{tabular}

\section{Nota: Legenda:}

$\mathrm{N}$ arq c $\mathrm{f}$ sup = não arquitetos com formação superior;

Resp s f sup = respondentes sem formação superior;

n.a $(\%)$ = número absoluto de entrevistados que mencionaram a justificativa em questão (porcentagem de entrevistados em relação às amostras individuais ou total de entrevistados cujas avaliações foram afetadas pela familiaridade e valor histórico - Tabela 5, que mencionaram a justificativa em questão);

alguns respondentes utilizaram dois motivos para explicar a influência da familiaridade ou valor histórico. 
Adicionalmente, considerando-se as informações obtidas por meio das entrevistas (Tabela 5), observa-se que a maioria do total dos 180 entrevistados, dos 60 arquitetos e dos 60 entrevistados sem formação universitária explicou que a avaliação da cena não foi afetada pelo fato de ela ser percebida ou não como sendo antiga ou tendo valor histórico. Salienta-se que o maior número de entrevistados com essa opinião está no grupo dos arquitetos, justamente aqueles que poderiam ser mais afetados pelo valor histórico da cena devido a sua formação acadêmica, que inclui história da arquitetura e das cidades. Segundo explica um entrevistado do grupo dos arquitetos, "o valor histórico em si não afetou a minha avaliação, porém os elementos que compõem as edificações antigas, por serem mais rebuscados e detalhados, fazem com que a edificação se torne mais rica em termos de ritmo, formas e composição". Nesse sentido, outro respondente, do grupo daqueles sem formação universitária, comentou não ter sido influenciado pelo valor histórico, mas pela riqueza de detalhes das cenas.

Contudo, a quantidade daqueles com opinião oposta não pode ser desprezada, seja no total, seja em cada um desses dois grupos (Tabela 5). Por outro lado, a maioria dos 60 não arquitetos com formação universitária informou que a avaliação da cena foi afetada pelo fato de ela ser percebida ou não como sendo antiga ou tendo valor histórico (Tabela 5).

Considerando a amostra total de entrevistados que se disseram afetados pelo valor histórico das cenas em suas avaliações (77 - Tabelas 5 e 6), o motivo mais citado para explicar tal efeito foi a "preferência devido a aspectos compositivos". Logo, esse resultado evidencia que pelo menos alguns entrevistados estavam referindo-se às características formais das cenas históricas, e não às associações possibilitadas por tais cenas, associações estas que porventura pudessem afetar as avaliações estéticas. Nesse sentido, somente um entrevistado afirmou conhecer a história de determinadas edificações e ter sido influenciado por esse conhecimento (Tabela 6). Outros motivos, bem menos citados, incluem:

(a) a cena remete a lembranças;

(b) propensão a gostar do que está acostumado;

(c) a cena representa a identidade e memória local; e

(d) prestígio agregado a cenas antigas (Tabela 6).

Sintetizando, os resultados indicam que o valor histórico de uma cena não afetou a avaliação e preferência por parte da clara maioria dos participantes na investigação. Ainda, mesmo entre vários daqueles que informaram que o valor histórico afetou suas avaliações, verificou-se que os aspectos formais e não simbólicos da cena é que realmente afetaram suas avaliações.

\section{Impacto do nível e tipo de formação na avaliação estética}

A existência ou não de diferenças entre as avaliações estéticas de pessoas com distintos níveis e tipos de formação é examinada por meio dos resultados obtidos com as avaliações de cada uma das nove cenas por cada um dos três grupos, e com a identificação das razões de tais avaliações e de diferenças entre elas através do teste KruskalWallis. Diferenças estatisticamente significativas quanto às avaliações estéticas das cenas entre os arquitetos, não arquitetos com formação universitária e aqueles sem formação universitária foram encontradas em relação a três das nove cenas:

(a) cena 1 (Figura 4 - cena histórica de Florença com ordem e pouco estímulo; Kruskal-Wallis, $\chi^{2}=$ 9,41, sig. = 0,006);

(b) cena 5 (Figura 8 - cena histórica de Porto Alegre com desordem; Kruskal-Wallis, $\chi^{2}=13,13$, sig. =0,001); e

(c) cena 9 (Figura 12 - cena contemporânea de Porto Alegre com ordem e pouco estímulo; Kruskal-Wallis test, $\chi^{2}=10,02$, sig.=0,005).

Essas diferenças estão relacionadas à melhor avaliação da cena 1 pelos arquitetos e à pior pelos respondentes sem formação universitária; à melhor avaliação da cena 5 pelos não arquitetos com formação universitária e à pior pelos arquitetos; e à melhor avaliação da cena 9 pelos arquitetos e à pior pelos não arquitetos com formação universitária (Tabela 1). Logo, essas diferenças estão baseadas na maior valorização estética da ideia de ordem e na maior desvalorização da ideia de desordem por parte dos arquitetos, em comparação aos outros dois grupos. Mesmo não havendo uma diferença estatisticamente significativa entre as avaliações das outras cenas por parte dos três grupos, a maior desvalorização das cenas 2 e 7 (com desordem) pelos arquitetos vai ao encontro dos resultados acima.

Diferenças estatisticamente significativas quanto às preferências pelas cenas entre os arquitetos, não arquitetos com formação universitária e aqueles sem formação universitária foram encontradas em quatro das nove cenas:

(a) cena 2 (Figura 5 - cena histórica de Florença com desordem; Kruskal-Wallis, $\chi^{2}=6,611$, sig. $=$ 0,037); 
(b) cena 5 (Figura 8 - cena histórica de Porto Alegre com desordem; Kruskal-Wallis, $\chi^{2}=$ 25,873 , sig. = 0,000);

(c) cena 8 (Figura 11 - cena contemporânea de Porto Alegre com ordem e estímulo; KruskalWallis, $\chi^{2}=11,143$, sig. $\left.=0,004\right)$; e

(d) cena 9 (Figura 12 - cena contemporânea de Porto Alegre com ordem e pouco estímulo; Kruskal-Wallis, $\chi^{2}=15,122$, sig. $=0,001$ ).

Essas diferenças estão relacionadas à maior preferência pela cena 2 por aqueles sem formação universitária e à menor pelos arquitetos; à maior preferência pela cena 5 por aqueles sem formação universitária e pelos não arquitetos com formação superior e à menor pelos arquitetos; à maior preferência pela cena 8 pelos arquitetos e à menor pelos não arquitetos com formação universitária; à maior preferência pela cena 9 pelos arquitetos e à menor pelos não arquitetos com formação universitária e por aqueles sem formação universitária (Tabela 2).

Portanto, essas diferenças evidenciam, novamente, a maior valorização estética da ideia de ordem e a maior desvalorização da ideia de desordem pelos arquitetos, em comparação aos outros dois grupos. Essas diferenças indicam também que o pouco estímulo visual em uma cena ordenada apresenta um potencial menor em tornar tal cena menos preferida que uma cena desordenada (em função da percepção de estímulo nesta) no grupo dos arquitetos do que nos outros dois grupos. Ainda, corrobora esses resultados o fato de que os percentuais das principais razões que justificam a cena mais preferida (similaridade entre as formas e similaridade entre as alturas) e a cena menos preferida (diferença entre as formas e diferença entre as alturas) são maiores entre os arquitetos do que nos outros dois grupos (Tabela 3). Especificamente, as principais razões citadas pelos arquitetos para justificar a cena 5 como a menos preferida são as diferenças entre as alturas e entre as formas das edificações que integram a cena (Tabelas 2 e 3). Por outro lado, a cena 9 foi justificada como a menos preferida por não arquitetos com formação universitária devido à similaridade entre as formas (Tabelas 2 e 3). Nesse sentido, conforme já salientado, a "similaridade entre as formas" foi um pouco mais mencionada do que a "diferença entre as formas" como razão para a cena menos preferida para os não arquitetos com formação universitária (Tabela 3). Contudo, conforme evidenciado pelo fato de as cenas 3 (Figura 6 - cena histórica de Praga com ordem e estímulo) e 4 (Figura 7 - cena histórica de Porto Alegre com ordem e estímulo) serem as duas cenas mais bem avaliadas individualmente (Tabela 1
Quadro 1) e as duas cenas mais preferidas (Tabela 2) por cada um dos três grupos, quando a ideia de ordem está presente e o estímulo visual é claramente percebido, a resposta estética é positiva, independentemente do tipo e do nível de formação.

\section{Conclusões}

O exame da dicotomia entre a abordagem da estética filosófica e a da estética empírica, através dos resultados obtidos com as avaliações individuais das nove cenas com diferentes níveis de ordem e estímulo visual, assim como com as preferências por elas, revelou que cenas com distintos níveis de ordem e estímulo visual são avaliadas diferentemente. As explicações estão no impacto estético positivo da ideia de ordem e estímulo visual e na tendência do impacto estético negativo da ideia de desordem ou da falta de organização. Contudo, a ideia de ordem pode não ser suficiente para produzir respostas estéticas positivas se o estímulo for muito pequeno, caracterizando um conjunto arquitetônico que pode ser percebido como monótono. Nesse sentido, a similaridade entre as formas e a similaridade entre as alturas foram mencionadas pelos respondentes como as principais razões para justificar as cenas mais preferidas. Por outro lado, as diferenças entre as formas e entre as alturas foram mencionadas como as principais razões para justificar as cenas menos preferidas, embora a similaridade entre as formas também possa explicar a cena menos preferida. Assim, esses resultados suportam a abordagem da estética empírica, que procura entender as razões para avaliações estéticas positivas e negativas (LANG, 1987), entendimento este que a abordagem da estética filosófica descarta como possível, conforme argumentado por Ruskin (1885 ${ }^{18}$ apud LANG, 1987).

A análise do impacto da estética formal e da estética simbólica, através dos resultados provenientes das avaliações individuais das nove cenas com diferentes níveis de familiaridade e valor histórico, assim como com as preferências por elas, indica que um maior nível de familiaridade com a cena não foi determinante para sua avaliação positiva, embora a familiaridade possa ter um impacto estético positivo. Ainda, a percepção da cena como familiar ou não familiar não estava necessariamente vinculada ao fato de as edificações serem da cidade do respondente (Porto Alegre) ou de uma cidade em outro país (Florença ou Praga). Assim, esses resultados indicam que o fato de uma cena urbana ser mais conhecida do

\footnotetext{
${ }^{18}$ RUSKIN, J. Stones of Venice. Boston: Estes and Lauriat
} Publishers, 1885. 
que outra não necessariamente implica que a mais conhecida será mais bem avaliada, o que não sustenta a afirmação de Porteous (1996) acerca da clara influência da familiaridade sobre as avaliações estéticas das pessoas. Contudo, tais resultados vão ao encontro da declaração de que a familiaridade pode afetar a preferência estética (NASAR, 1998)

A existência de valor histórico também não foi determinante para uma avaliação mais positiva ou uma maior preferência pela cena. Ficou também evidenciado que pelo menos parte das referências ao valor histórico para explicar avaliações estéticas positivas, na verdade, dizia respeito aos atributos formais das edificações históricas constituintes das cenas. Assim, esses resultados sustentam uma das possibilidades cogitadas por Nasar (1998), no sentido de que as pessoas podem avaliar edificações e cenas históricas positivamente devido à existência de ordem e variedade (estímulo) numa combinação percebida como adequada. Portanto, bem mais do que a estética simbólica, a estética formal parece explicar as avaliações estéticas das pessoas.

Com relação ao exame da existência ou não de diferenças entre as avaliações estéticas de pessoas com distintos níveis e tipos de formação, por meio dos resultados obtidos com as avaliações individuais de cada uma das nove cenas por cada um dos três grupos, assim como com as preferências por elas, constata-se uma maior valorização estética da ideia de ordem e uma maior desvalorização da ideia de desordem por parte dos arquitetos, em comparação ao grupo dos não arquitetos com formação universitária e ao grupo daqueles sem formação universitária, que parecem necessitar de um nível maior de estímulo visual. Assim, é menor no grupo dos arquitetos do que nos outros dois grupos a possibilidade do pouco estímulo visual numa cena ordenada torná-la menos preferida que uma cena desordenada. Contudo, quando a ideia de ordem está presente e o estímulo visual é claramente percebido, a resposta estética é positiva, independentemente do tipo e do nível de formação. Logo, esses resultados não corroboram aqueles que indicam a existência de diferenças significativas entre as preferências estéticas de arquitetos e leigos com relação a fachadas de edifícios (FAWCETT; ELLINGHAM; PLATT, 2008)

Finalizando, os resultados desta investigação possibilitam uma melhor compreensão acerca da estética urbana, incluindo as razões que tendem a justificar uma avaliação estética positiva ou negativa do espaço urbano. Tal compreensão possibilita que a estética das cidades seja considerada no planejamento visando à melhoria da qualidade urbana.

\section{Referências}

ARNHEIM, R. The Dynamics of Architectural Form. Berkeley and Los Angeles: University of California Press, 1977.

FAWCETT, W.; ELLINGHAM, I.; PLATT, S. Reconciling the Architectural Preferences of Architects and the Public: the ordered preference model. Environment and Behavior, v. 40, n. 5, p. 599-618, set. 2008.

GROAT, L. Contextual Compatibility in Architecture: an issue of personal taste? In: NASAR, J. Environmental Aesthetics: theory, research, and applications. Cambridge, UK: Cambridge University Press, 1988. p. 228-253.

HEATH, T. Behavioral and Perceptual Aspects of the Aesthetics of Uurban Environments. In: NASAR, J. (Ed.). Environmental Aesthetics: theory, research, and applications. Cambridge, UK: Cambridge University Press, 1988. p. 6-10.

LANG, J. Symbolic Aesthetics in Architecture: toward a research agenda. In: NASAR, J.

Environmental aesthetics: theory, research, and applications. Cambridge, UK: Cambridge University Press, 1988. p. 11-26.

LANG, J. Creating Architectural Theory: the role of the behavioural sciences in environmental design. New York: Van Nostrand Reinhold, 1987.

LOZANO, E. Visual Needs in Urban

Environments and Physical Planning. In: NASAR, J. Environmental Aesthetics: theory, research, and applications. Cambridge, UK: Cambridge University Press, 1988. p. 395-421.

MARTINDALE, C. Aesthetics, psychobiology, and cognition. In: FARLEU, F.; NEPERUD, R.

The foundations of aesthetics, art, \& art education. New York: Praeger, 1988. p. 7-42.

NASAR, J. New developments in Aesthetics for Urban Design. In: MOORE, G. T.; MARANS, R. W. Advances in Environment, Behavior, and Design: toward the integration of theory, methods, research, and utilization. New York: Plenum, 1997. v. 4, p. 149-193.

NASAR, J. The Evaluative Image of the City. Thousand Oaks, CA: Sage, 1998.

PORTEOUS, J. D. Environmental Eesthetics: ideas, politics and planning. London: Routledge, 1996. 
PRAK, N. The Visual Perception of the Built Environment. Delft: Delft University Press, 1985.

PURCELL, A. T. The Aesthetic Experience and Mundane Reality. In: CROZIER, W. R.; CHAPMAN, A. J. Cognitive Processes in the Perception of Art. Amsterdam: North-Holland, 1984. p. 189-210.

REIS, A.; LAY, M. C. Avaliação da Qualidade de Projetos: uma abordagem perceptiva e cognitiva. Revista Ambiente Construído, Porto Alegre, v. 6, n. 3, p. 21-34, jul./set. 2006.

REIS, A.; LAY, M. C. Habitação de Interesse Social: uma análise estética. Revista Ambiente Construído, Porto Alegre, v. 3, n. 4, p. 7-19, out./dez. 2003.

REIS, A. Aparência, Qualidade e Habitação Sustentável. In: ENCONTRO NACIONAL DE TECNOLOGIA DO AMBIENTE CONSTRUIIDO, 9., Foz do Iguaçu, 2002. Anais... Foz do Iguaçu: Antac, 2002. p. 1105-1112.

SADAN, E.; CHURCHMAN, A. Global Sustainability and Community Empowerment. In: INTERNATONAL ASSOCIATION FOR PEOPLE-ENVIRONMENT STUDIES, 14., Stockholm, 1997. Proceedings... Stockholm, Sweden: Royal Institute of Technology (KTH), The Department of Architecture and Townplanning, 1997. p. 184-192.
SANOFF, H. Visual Research Methods in Design. New York: Van Nostrand Reinhold, 1991.

VON MEISS, P. Elements of Architecture: from form to place. London: E \& FN Spon, 1993.

WEBER, R. On the Aesthetics of Architecture, a Psychological Approach to the Structure and the Order of Perceived Architectural Space. Aldershot, UK: Avebury, 1995.

\section{Agradecimentos}

Além dos agradecimentos ao $\mathrm{CNPq}$ e à FAPERGS, pelo apoio financeiro para a realização desta pesquisa, agradecimentos são prestados à RS Projetos, pelas fotografias cedidas, ao IPHAN, IPHAE, e EPAHC, pela lista das edificações tombadas, e aos docentes e funcionários da UFRGS, assim como aos arquitetos de outras instituições e escritórios privados que participaram desta pesquisa.

Revista Ambiente Construído

Associação Nacional de Tecnologia do Ambiente Construído

Av. Osvaldo Aranha, $99-3^{\circ}$ andar, Centro

Porto Alegre - RS - Brasil

CEP $90035-190$

Telefone: +55 (51) 3308-4084

Fax: +55 (51) 3308-4054

www.seer.ufrgs.br/ambienteconstruido

E-mail: ambienteconstruido@ufrgs.br

204 Reis, A. T. da L.; Biavatti, C. D.; Pereira, M. L. 